منجلة النبحوث الكالية والنتجارية

$$
\text { المجلد (22) - العدد الأول - يناير } 2021
$$

\title{
أثر الإرهاب على النمو الاقتصادى فى مصر خلال الفترة 1996-2018
}

\author{
د/ ضياء فتحى العدل \\ مدرس الاقتصاد \\ المعه العالى للعلوم الإدارية بالمنزية
}

The Impact of Terrorism on Economic Growth in Egypt during the Period 1996-2018

\author{
Dr. Diaa Fathy El-Adl
}

Higher Institute of Management Sciences, El-Manzala 


\section{مستخلص}

تحاول هذه الاراسة تقدير أثر الإرهاب على النمو الاقتصادى فى مصر خلال الفترة

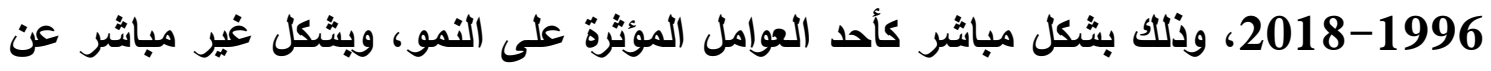

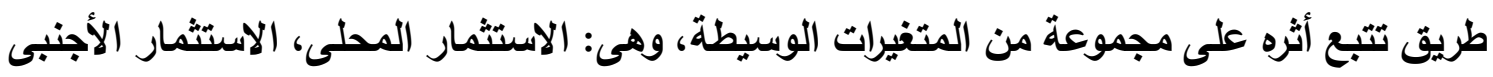

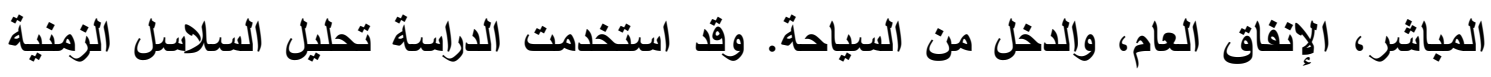

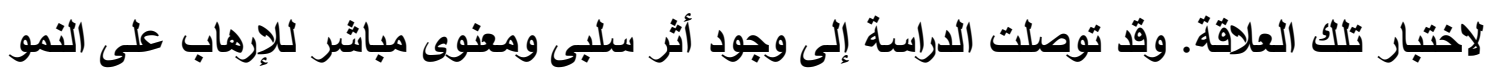

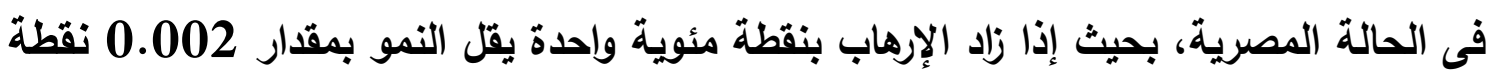

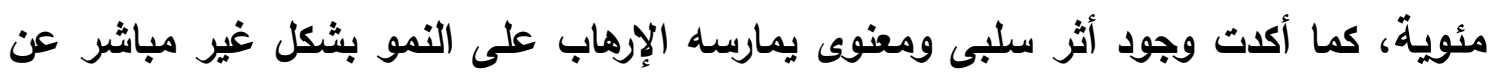

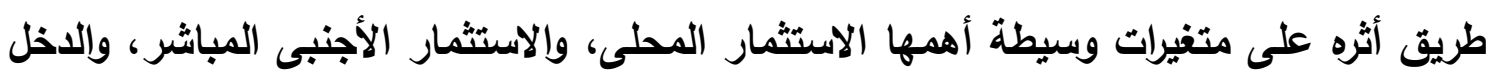

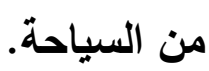

وتوصى الاراسة بناءً على ذلك بتبنى استراتيجية متكاملة لمكافحة الإرهاب تثتنمل على

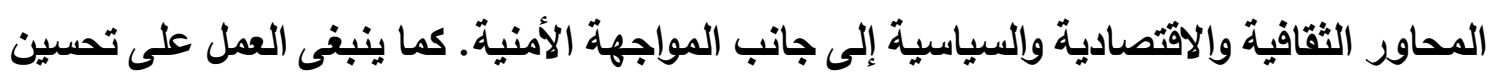

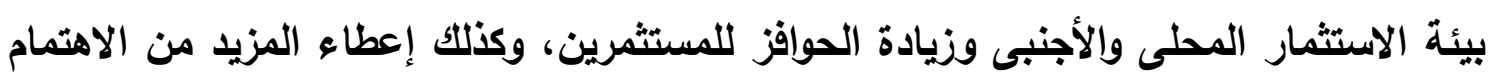

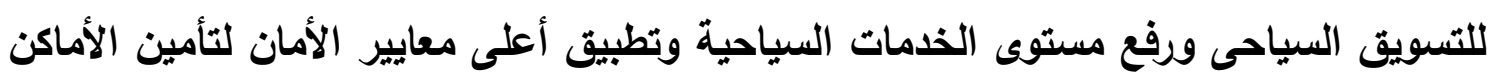
السياحية والمطارات، وذلك لمواجهة الأثر السلبى المحتمل للإرهاب على السياحة.

الكلمات المفتاحية: الإرهاب، النمو الاقتصادى، الاستثمار المحلى، الاستثمار الأجنبى المباشر، الإنفاق الحكومى، الدخل من السياحة. 


\title{
The Impact of Terrorism on Economic Growth in Egypt during the Period 1996-2018
}

Diaa Fathy El-Adl

\begin{abstract}
$\underline{\text { Abstract }}$
This study attempts to estimate the impact of terrorism on economic growth in Egypt during the period 1996-2018, directly as one of the factors affecting growth, and indirectly by tracking its impact on a set of channel variables, which are: domestic investment, direct foreign investment, public spending, and income from tourism. The study used time series analysis to test this relationship. The study found that there is a direct negative and significant effect of terrorism on growth in the Egyptian case, so that if terrorism increases by one percentage point, growth decreases by 0.002 percentage points. It also confirmed the existence of a negative and significant impact that terrorism exerts on growth indirectly through its effect on channel variables, the most important of which are: domestic investment, foreign direct investment, and income from tourism.

Accordingly, the study recommends adopting an integrated strategy to combat terrorism that includes cultural, economic and political axes, as well as security confrontation. It should also work to improve the environment for local and foreign investment and increase incentives for investors, as well as give more attention to tourism marketing, raise the level of tourism services, and apply the highest safety standards to secure tourist places and airports, in order to counter the potential negative impact of terrorism on tourism.
\end{abstract}

key words: Terrorism, economic growth, domestic investment, foreign direct investment, income from tourism. 


\section{1- مقدمة:}

تعانى كثير من المجتمعات، وخاصة المجتمعات العربية والإسلامية ومنها مصر ، من تنامى

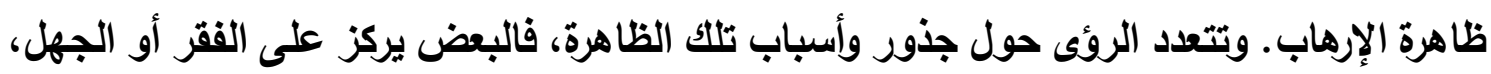

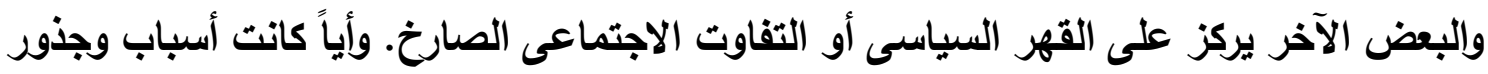

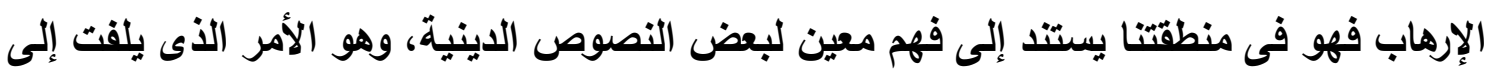

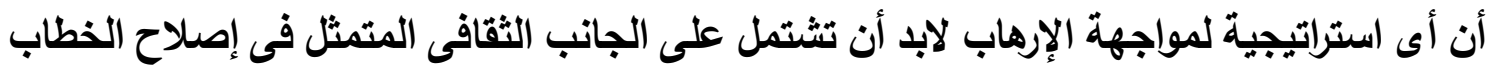
الدينى. وللإرهاب آثار مباشرة على النشاط الاقتصادى تنتج من تدمير جزء من الموارد البشرية

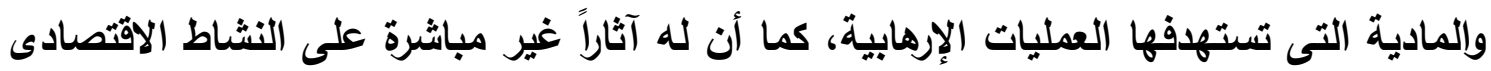

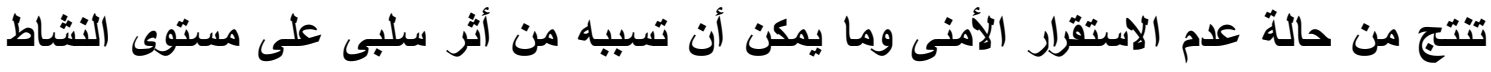
الاقتصادى القائم فى قطاعات عديدة وكذلك على معدلات الاستثمار المحلى والخارجى. كما يمثل الإنل الإرهاب عبئاً على الموارد العامة المحدودة للاولة، حيث تضطر الدولة إلى توجيه المزيل من الموارد إلى مواجهته وذلك بالطبع على حساب الموارد الموجهة إلى تطوير الخدمات والبنية الأساسية

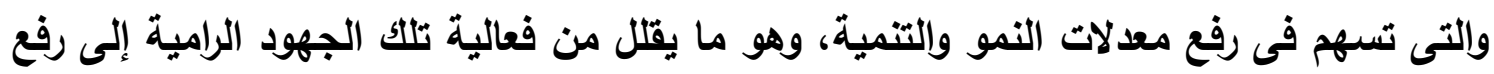
معدلات النمو والتنمية. لذا فإن الحاجة ماسة إلى مزيد من التحليل لظاهرة الإرهاب سواء من ناحية داوفعه وجذوره أو من ناحية آثاره المختلفة ويخاصة الاقتصادية منها بغية تحديد حجم المشكلة واختيار استراتيجية الحل الملائمة لها، وهذا البحث هو محاولة تضاف إلى المحاولات القائمة فى هذا السبيل. 1/1

للإرهاب أثر سلبى مباشر وغير مباشر على النمو الاقتصادى؛ فعن طريق ما يدمره الإرهاب

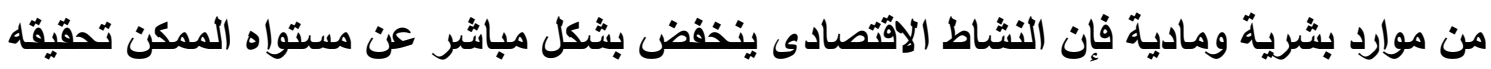

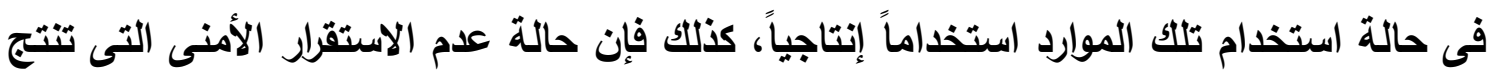
من الإرهاب تؤثر سلباً على مجموعة من المتفيرات الوسيطة channel variables مثل:

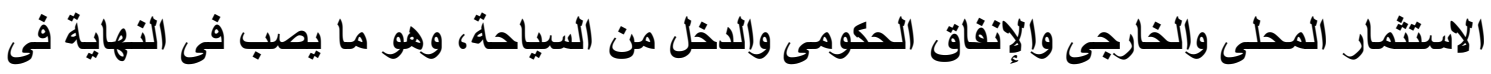

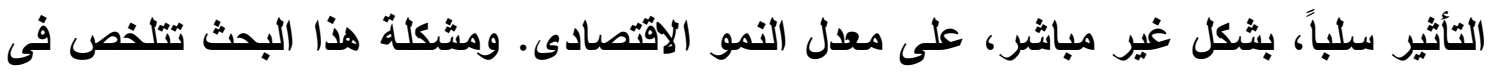

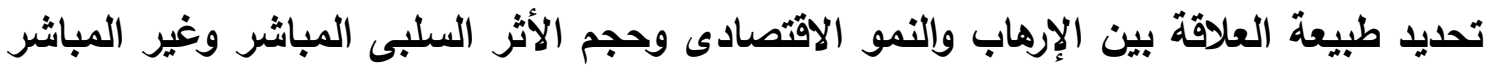

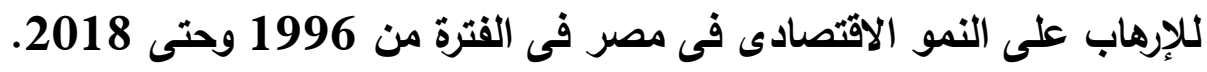
2/1 فروض البحث: 201 
يحاول البحث أن يختبر مدى صحة الفروض التالية: - وجود أثر سلبى ومعنوى للإرهاب على كل من الاستثمار المحلى والاستثمار الخارجى المباشر واللاخل من السياحة خلال فترة البحث.

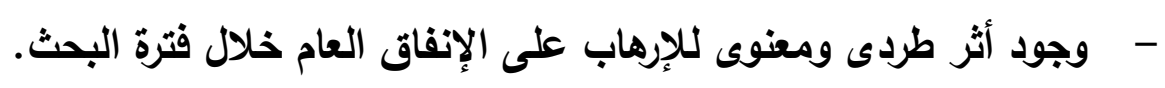

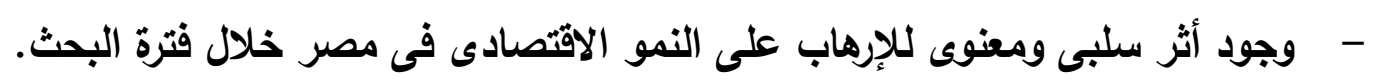
3/1 تساؤلات البحث: يحاول البحث الإجابة على التساؤلات التالية:

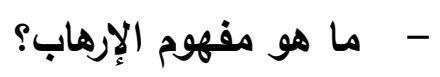

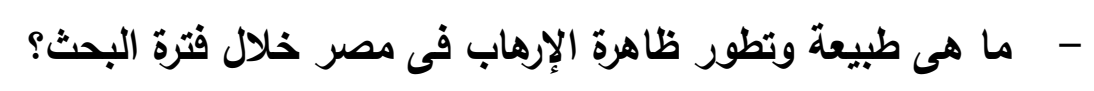

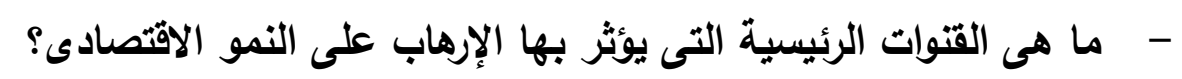

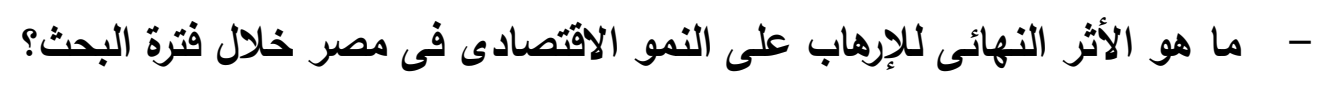

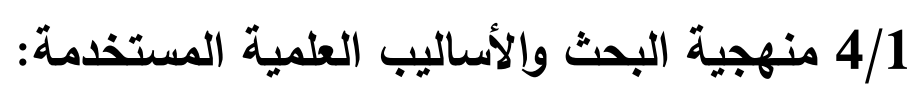

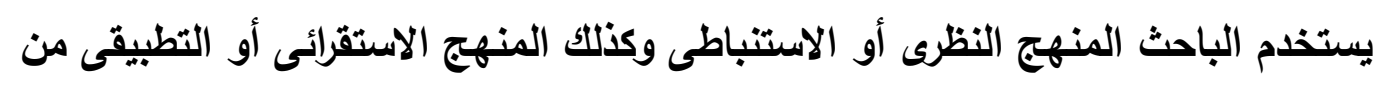

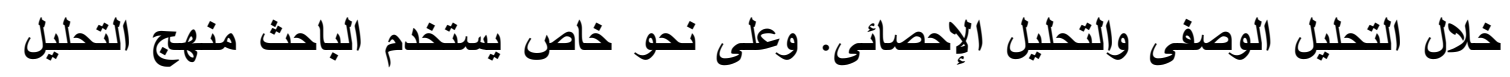

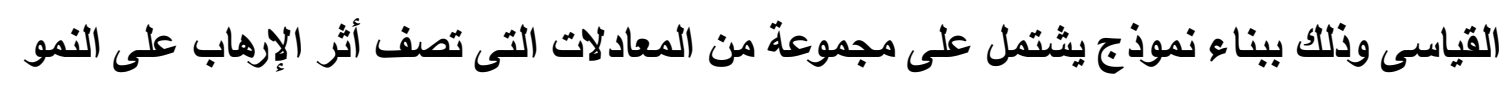
بثكل مباشر، كما تصف أثر الإرهاب على مجموعة من المتغيرات الوسيطة المحددة للنمو.

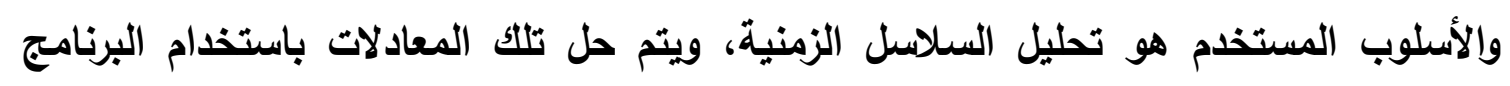

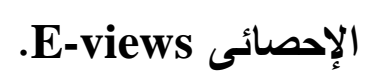
5/1

ينقسم البحث بعد المقدمة إلى ثلاثة أقسام:

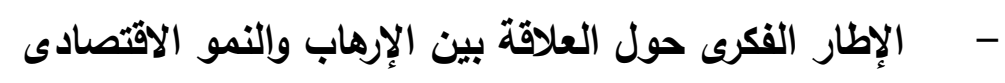

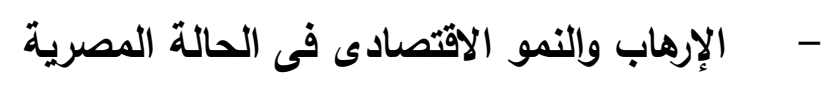

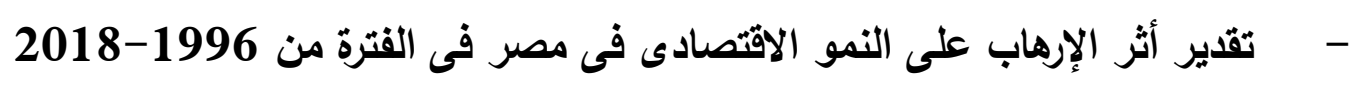
- - النتائج والتوصيات والاقتراحات الخاصة بالدراسات المستقبلية.

2- الإطار الفكرى حول العلاقة بين الإرهاب والنمو الاقتصادى 
نتناول فى هذا الجزء من البحث نتائج بعض الدراسات التى تعرضت لموضوع أثثر الإرهاب

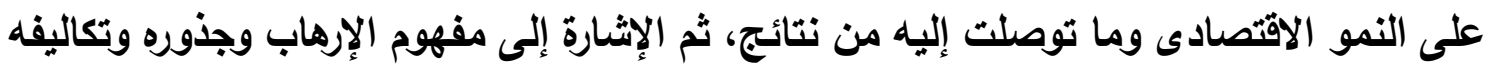

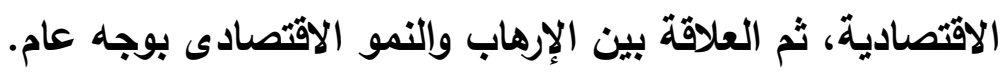

1/2

تناولت دراسات عديدة أثر الإرهاب على النمو الاقتصادى، سواء كان ذلك على المستوى

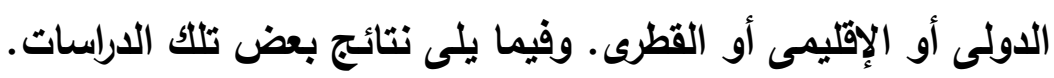

: Zakaria \& Others, 2019) (رراسة

تبحث هذه الاراسة أثر الإرهاب على النمو الاقتصادي في باكستان فى الفترة 1972-2014، وذلك من خلال دراسة أثره على الاستثمار الأجنبي المباشر ، والاستثمار المحلي، والإنفاق الحكومى.

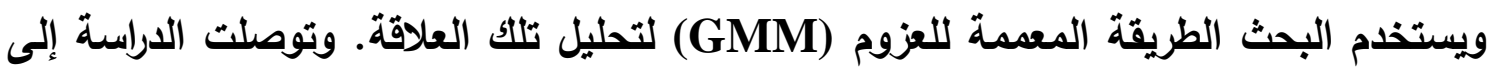
وجود علاقة عكسية معنوية بين الإرهاب والنمو الاقتصادى بشكل مباشر ، كما توصلت إلى وجود

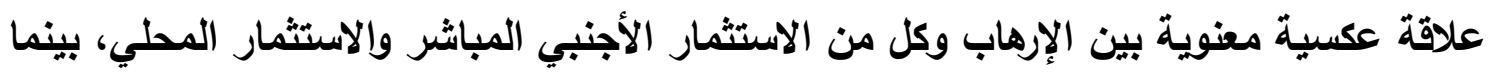

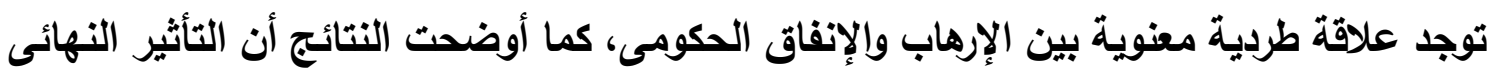
غير المباشر للإرهاب على النمو الاقتصادى كان سلبياً.

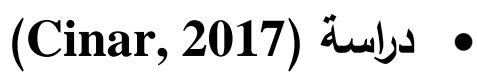

تهاف هذه الدراسة إلى تقدير آثار الإرهاب على النمو الاقتصادى من منظور عالمى. وتفطى

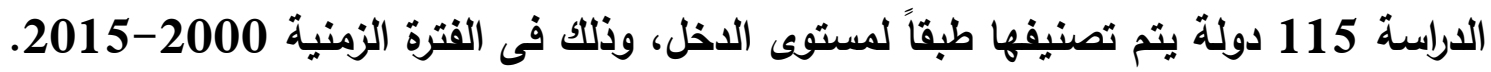
وتعتمد الدراسة على تحليل حزم البيانات المقطعية الزمنية. ولقد توصلت إلى أنه كان للهجمات

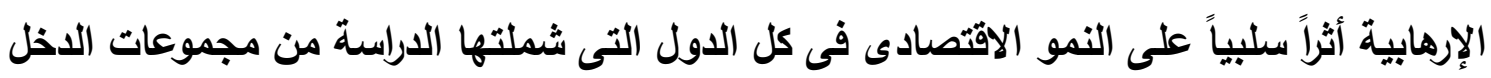

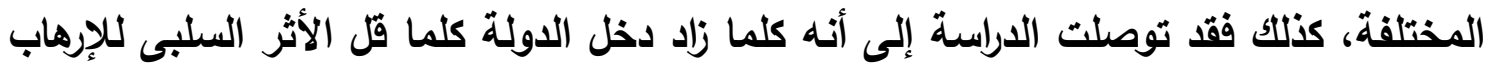

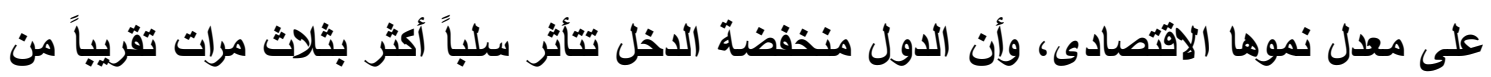
الدول ذات الاخل الأعلى نتيجة لهذه الهجمات الإرهابية.

دراسة (مصطقى، 2013):

تقوم تلك الاراسة بتحليل أثر الإرهاب على معدل النمو الاقتصادى فى مصر فى الفترة

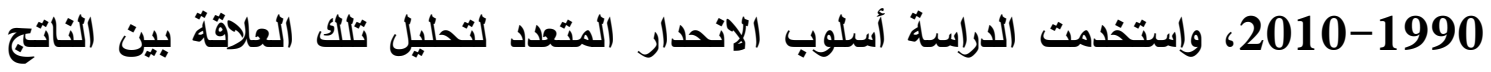

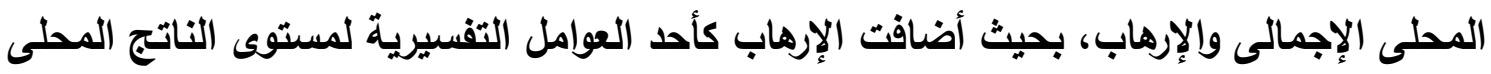


الإجمالى إلى جانب الاستثمار الأجنبى المباشر وإيرادات قطاع السياحة والإنفاق الحكومى. وقد

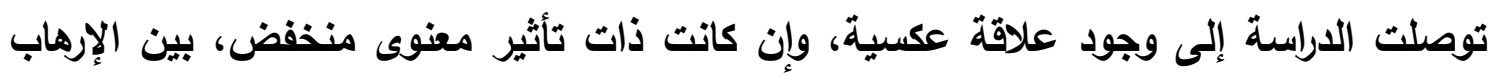

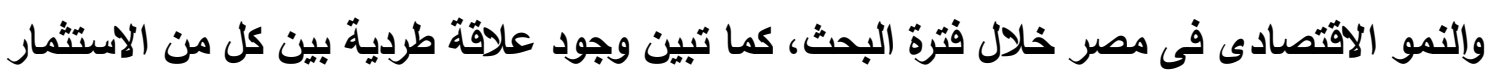

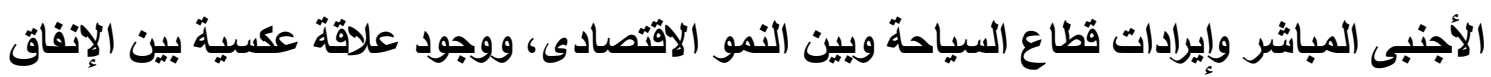

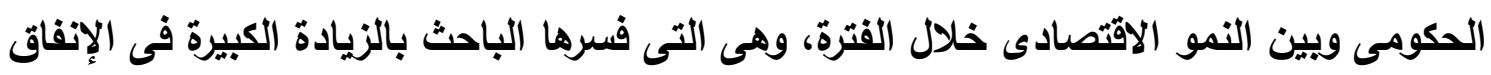

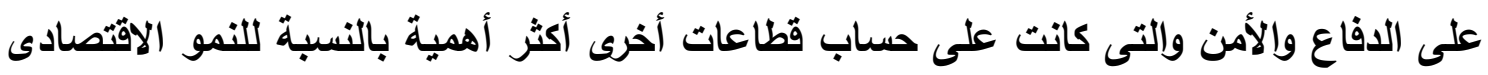

$$
\text { فى مصر . }
$$

(Meierrieks \& Gries, 2012) دراسة •

تهذف هذه الاراسة إلى اختبار العلاقة العببية بين الإرهاب والنمو الاقتصادى، وذلك

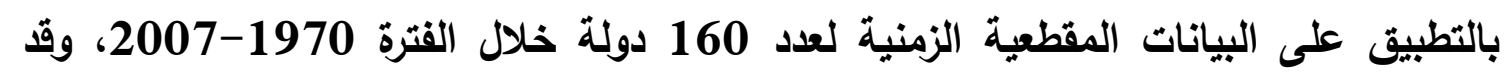

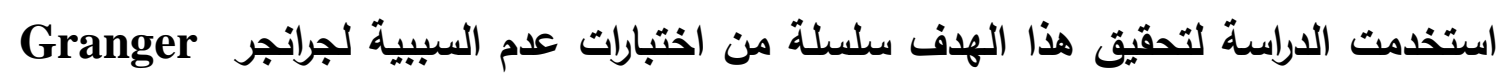

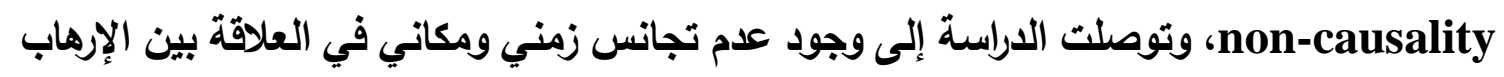

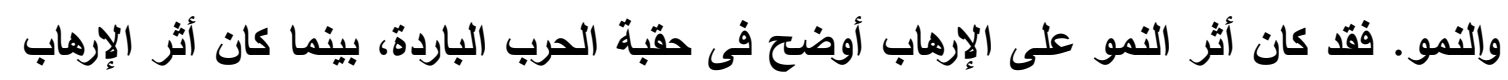

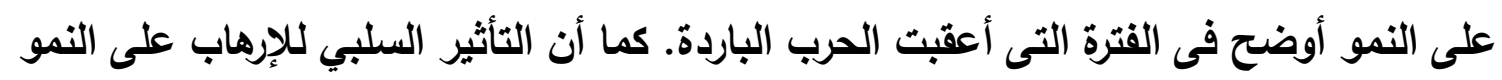

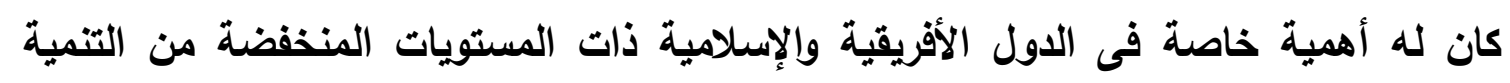

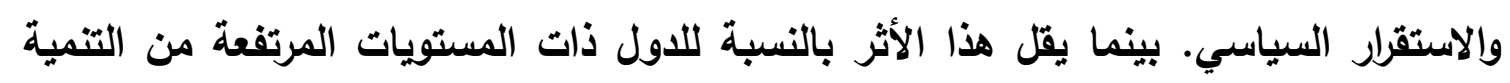
والاستقرار السياسى.

\section{دراسة (Ocal \& Yildrim, 2010)}

تهدف هذه الدراسة إلى تقدير أثر الإرهاب على النمو الاقتصادى فى محافظات تركيا فى

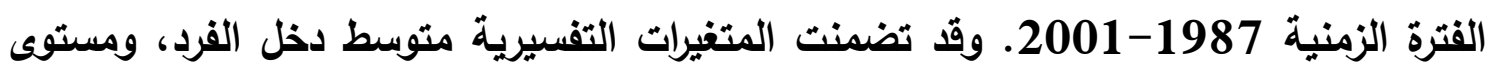
التعليم، ومستوى الإنفاق العام، إلى جانب الإرهاب. وقد استخدمت الدراسة نموذج الانحدار المرجح

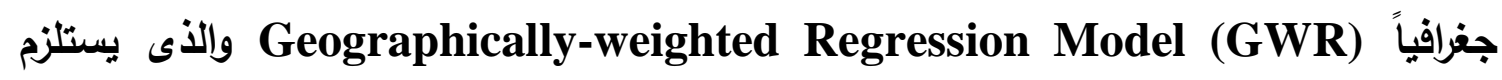
فصص الاختلافات المكانية بين المناطق بهذف تقدير المعلمات الخاصة بكل منطقة من المناطق

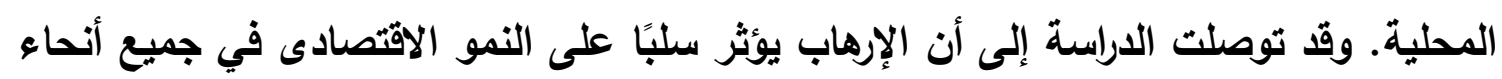

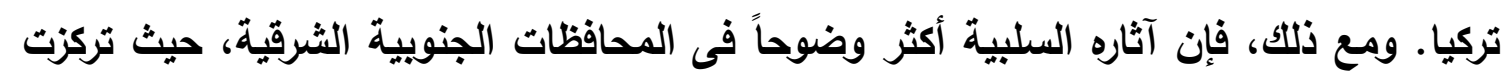

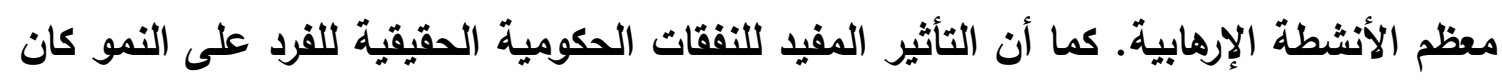
أقوى بكثير فى المحافظات الوسطى والغربية الأكثر تطوراً. 
دراسة (Gaibulloev \& Sandler, 2009):

تبحث هذه الاراسة فى أثر الإرهاب والصراعات على نمو متوسط دخل الفرد في آسيا فى

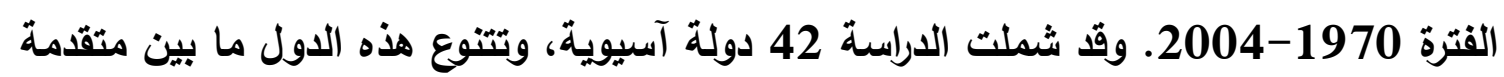
ونامية. وقد اعتمدت الاراسة على إدخال العنف السياسى كأحد المحدات الرئيسية للنمو

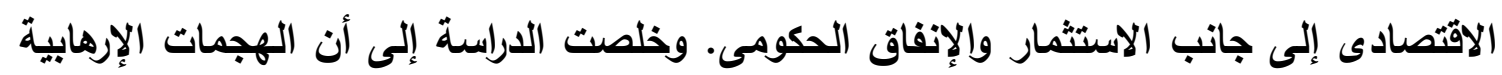

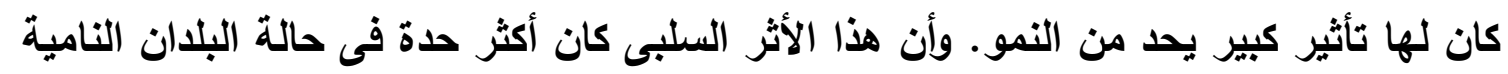

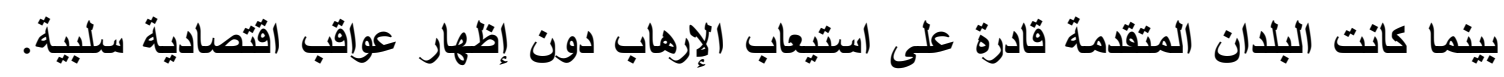
ويتركز هذا التأثير فى الانخفاض فى معدلات الاستثمار المحلى والأجنبى وزيادة الإنفاق الحكومى لإنى

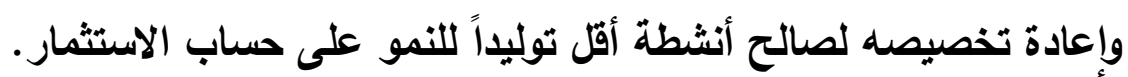
دراسة (Gaibulloev \& Sandler, 2008):

تهذف هذه الدراسة إلى تقدير أثر الإرهاب على نمو دخل الفرد وذلك باستخدام بيانات 18

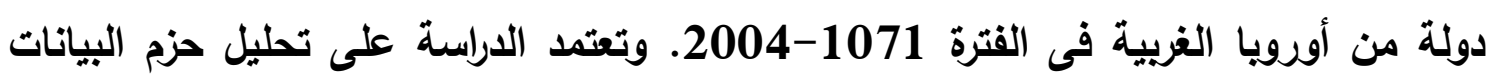
المقطعية الزمنية. وقد ميزت الاراسة بين نوعين من الحوادث الإرهابية: الحوادث الإرهابية العابرة

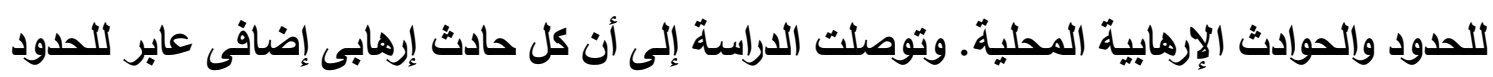

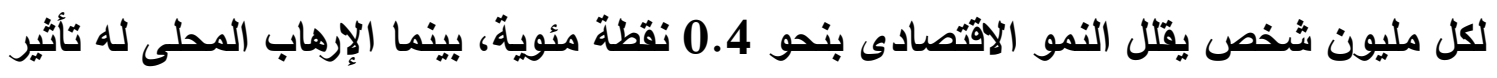

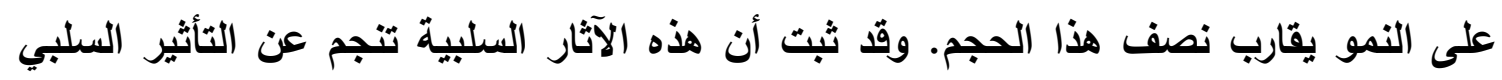

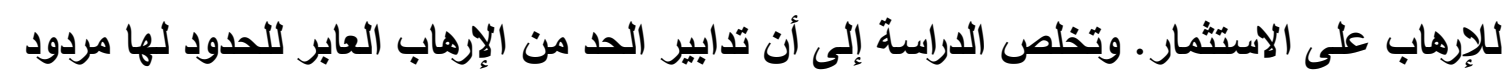
اقتصادى أكبر من التدابير المماثلة للحد من الهجمات الإرهابية المحلية.

\section{(Abadie \& Gardeazabal, 2008) • دراسة •}

تهاف هذه الاراسة إلى اختبار أثر مخاطر الإرهاب على تخصيص الاستثمار الأجنبى المباشر

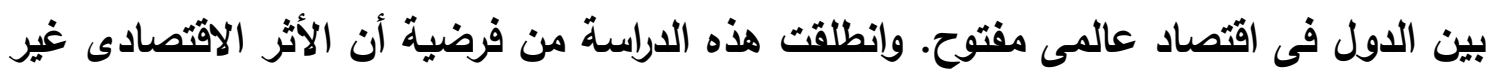

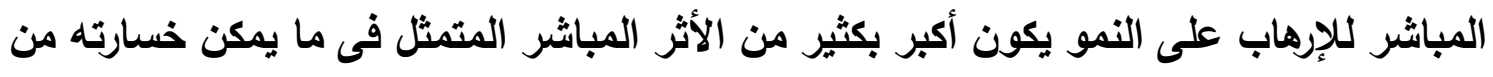

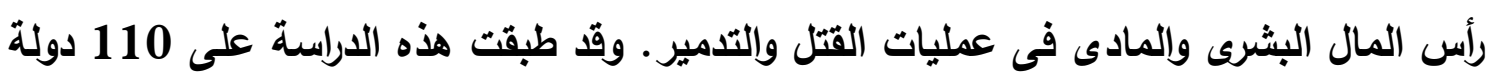
وإستخدم البيانات الخاصة بعام 2003. وتخلص الداسة ولمادئ إلى أنه بالإضافة إلى عدم اليقين

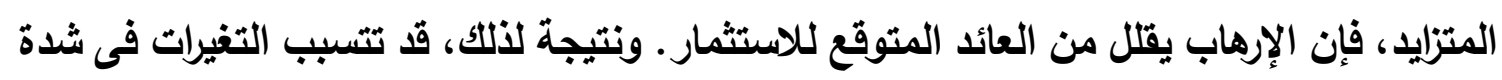
الإرهاب فى تحركات كبيرة لرأس المال بين الدول فى اقتصاد عالمى مفتوح، بحيث ترتبط المستويات 
الأعلى من مخاطر الإرهاب بمستويات أقل من صافى الاستثمار الأجنبي المباشر ، حتى بعد السيطرة على أنواع أخرى من المخاطر. ويمكن إجمال النتائج التى توصلت إليها الدراسات السابقة فيما يلى: - - - وجود أثر سلبى للإرهاب على النمو الاقتصادى بوجه عام.

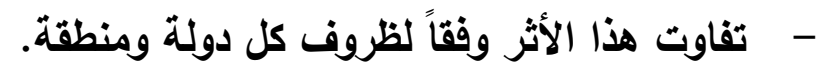
- - تعاظم الأثر الاقتصادى غير المباشر للإرهاب على النمو مقارنة بالأثر المباثر.

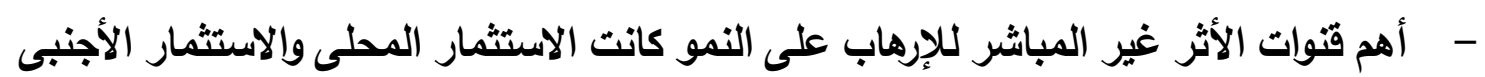
المباشر والإنفاق الحكومى. ونلاحظ من خلال الاراسات السابقة الندرة الثديدة فى الدراسات الخاصة بأثر الإرهاب على الإنى

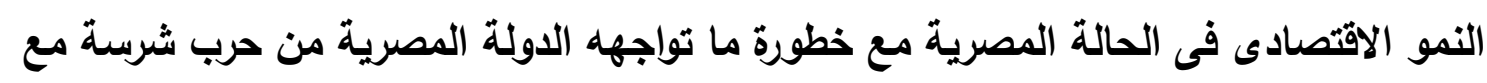

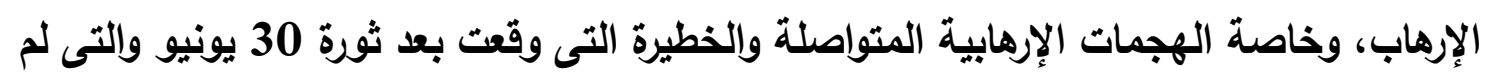
تثهر لها البلاد مثيلاً من قبل، وما لذلك من تأثير مؤكل على كل جوانب الإهابه النشاط الاقتصادى.

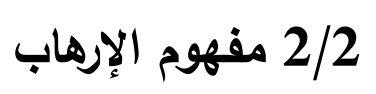

الإرهاب هو "الاستخدام المقصود أو التهايد باستخدام العنف تجاه المدنيين أو الأهداف

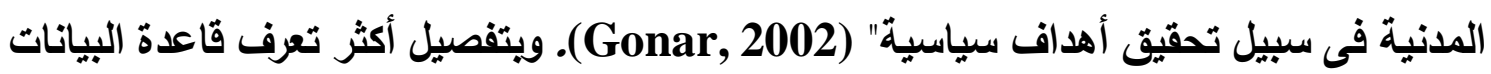
الدولية للإرهاب (GTD)

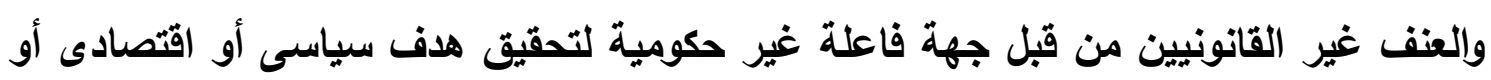

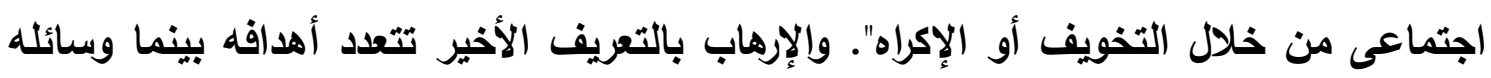
واحدة، التخويف أو الإكراه. واختلاف أهداف الإرهاب إنما يثير إلى اختلاف جذوره ودوافعه. ويمكن تقسيم الهجمات

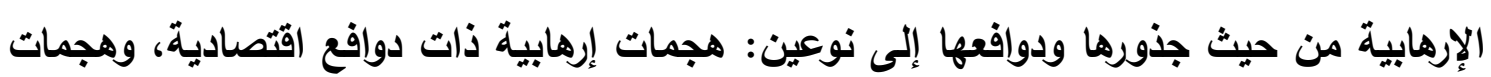
إرهابية ذات دوافع غير اقتصادية (Meierrieks \& Gries, 2012). والنوع الأول من الإرهاب ترجع أسبابه وجذوره إلى الظروف الاقتصادية والاجتماعية السيئة، ويهدف إلى تحسين تلكادية الظروف، وكانت معظم تلك الهجمات يقوم بها اليسار المتطرف فى أماكن كثيرة من العالم فى حقبة الهبة الحرب الباردة. بينما تراجع هذا النوع من الإرهاب بعد انتهاء الحرب الباردة ويرزت أثثكال أخرى

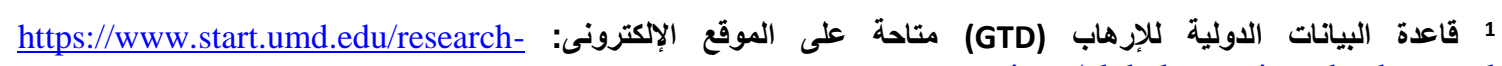
projects/global-terrorism-database-gtd 
من الإرهاب ذات جذور ودوافع غير اقتصادية تمثلت فى تلك الهجمات الإرهابية ذات الدوافع الثقافية الاينية والتى سادت في كثير من الدول الإسلامية.

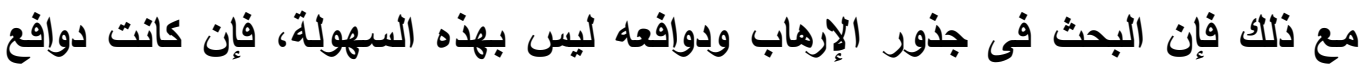

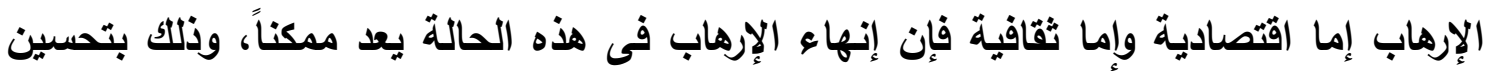
الظروف الاقتصادية والتعليم والثقافة. ولعله من المدهش أن مراجعتا للأدلة لا توفر سبياً يُنكر

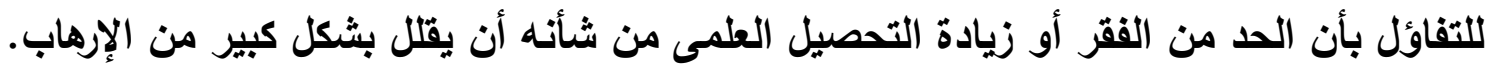
إن أى ارتباط بين الفقر والتعليم والإرهاب غير مباشر ومعقد وريما ضعيف للغاية، ويالتالى ريما يكون من الأجدى النظر إلى الإرهاب ليس فقط على أنه نتيجة مباشرة للفقر أو الجهل، ولكن ولكن أيضاً

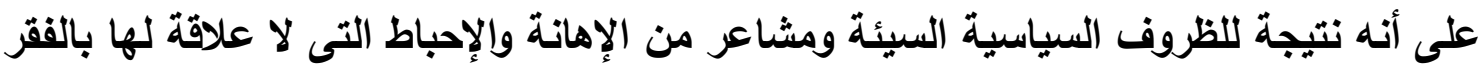
أو الجهل (Krueger \& Maleckova, 2003). 3/2 أثر الإرهاب على النمو الاقتصادى ألهات

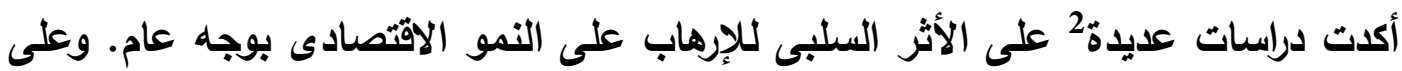

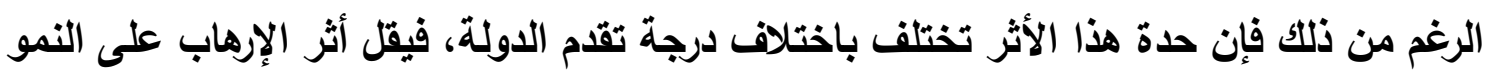
نسبياً فى الدول المتقدمة \& Cinar, 2017; Meierrieks \& Gries, 2012a; Enders \& Sandler, 2008) ملائمة للتقليل من حدة الخسائر الناجمة عن الإرهاب.

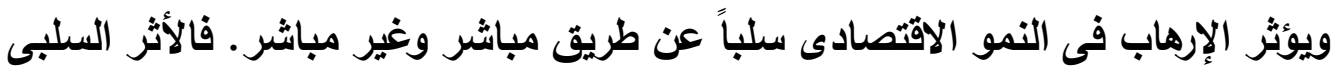

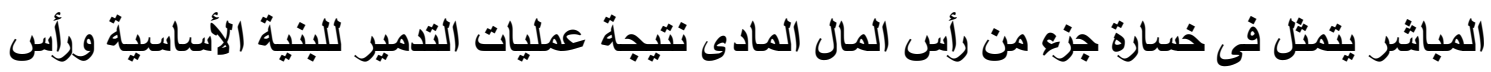

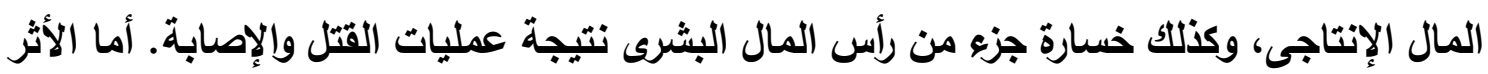

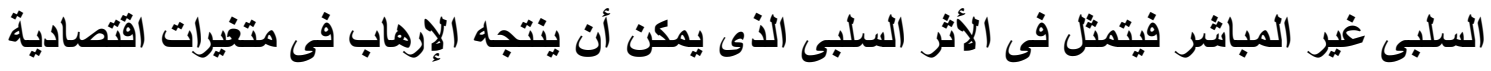

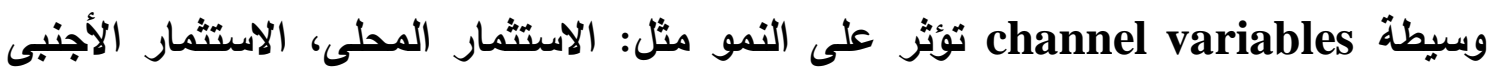
المباشر، التضخم، الإنفاق الحكومى، الأسواق المالية، البطالة، وغير ذلك ل \&akaria \& (Others, 2019; Frey \& others, 2007; Eckstein \& Tsiddon 2004) دراسة خاصة بمصر متغيراً وسيطاً هاماً فى الحالة المصرية وهو الاخل من السياحة (مصطفى،

Zakaria \& Others, 2019; Cinar, 2017; Blomberg \& others, 2011; Virgo, 2011; Ocal \& Yildrim, 2010; Gaibulloev \& Sandler, 2009; Gaibulloev \& Sandler, 2008; Enders \& Sandler, 2008; Mirza \& Verdier, 2008; Crain \& Crain, 2006; Blomberg, \& Orphanides, 2004; Tavares, 2004; Abadie \& Gardeazabad, 2003. 
1/3/2 أثر الإرهاب على الاستثمار الأجنبى المباشر

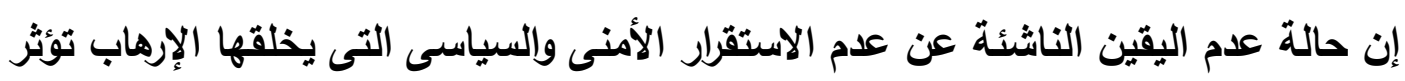

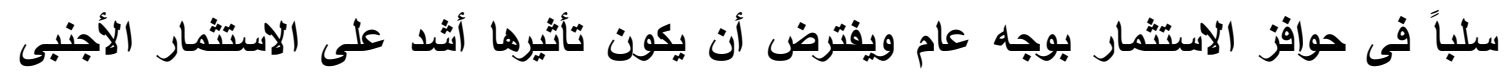

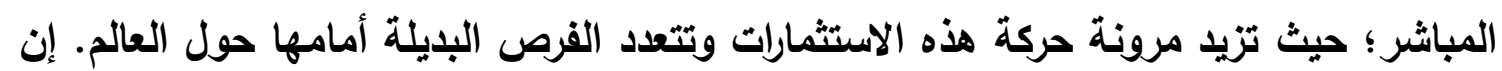

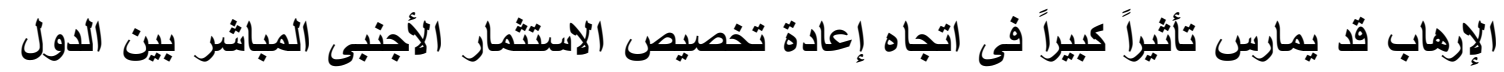

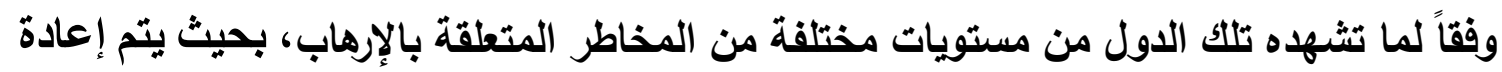

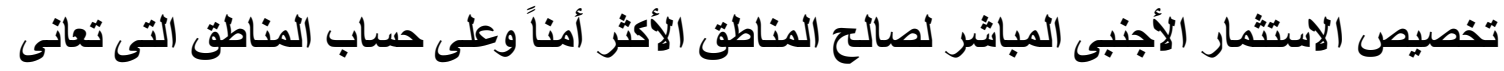
من وجود الإرهاب (Abadie \& Gardeazabal, 2008; Barth \& others, 2006)، ويلاحظ أن الدول النامية بالطبع هى الأكثر تضراً حيث تثثير إحدى الدراسات إلى الأثر السلبى

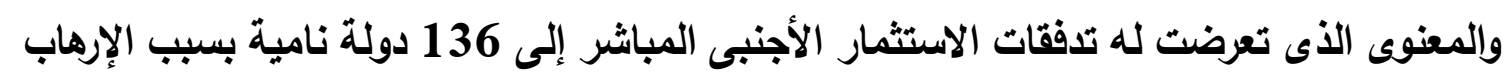
(Alomar \& El-Sakka, 2011). وحيث أن الاستثمار الأجنبى المباشر هو أحد مكونات

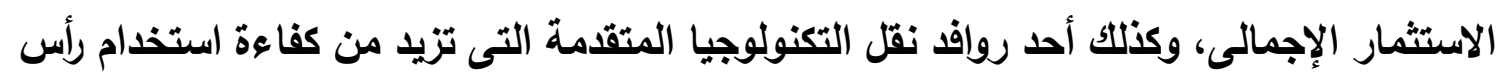

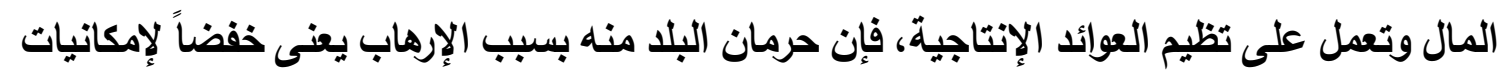
النمو الاقتصادى.

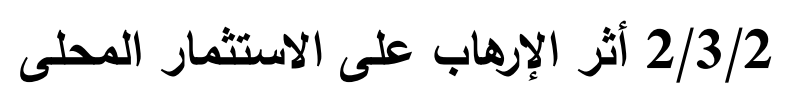

تفترض النظرية الاقتصادية أثراً سلبياً للإرهاب على الاستثمار المحلى والمدخرات وذلك الإلك

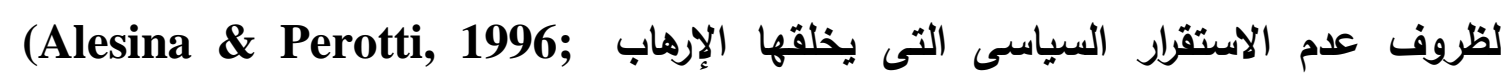
Venieris \& Gupta, 1986)

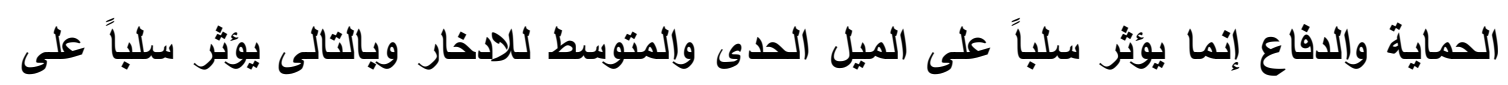

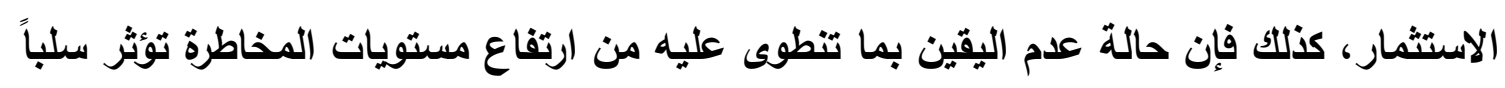

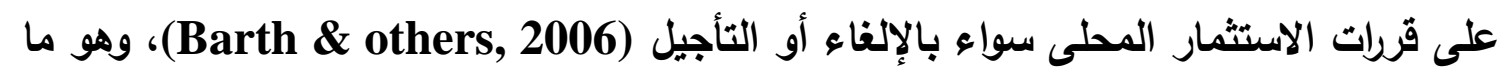
يؤثر سلباً على إمكانيات النمو.

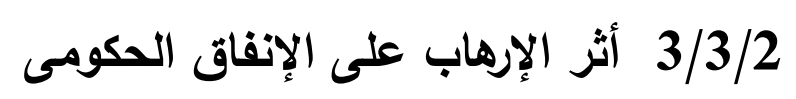

بمجرد وقوع حوادث إرهابية متكررة فإن على الحكومة الإبهاب أن توفر المزيد من خدمات الأمن

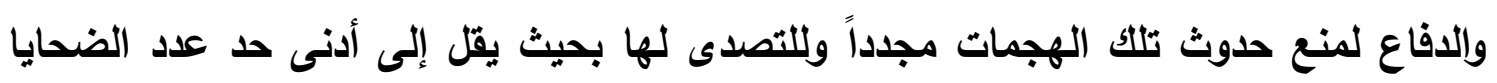

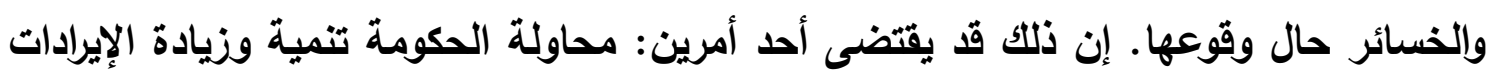

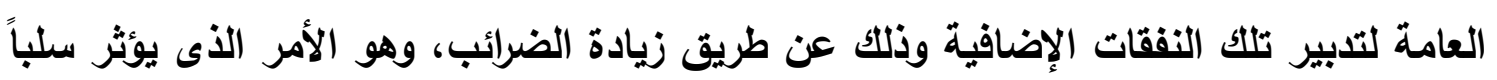

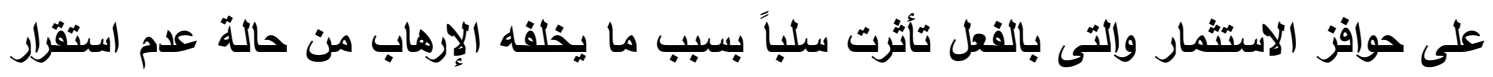


وارتفاع لارجات المخاطرة، فإذا ما تجنبت الحكومة هذا الإجراء فإنه ليس أمامها من سبيل إلا

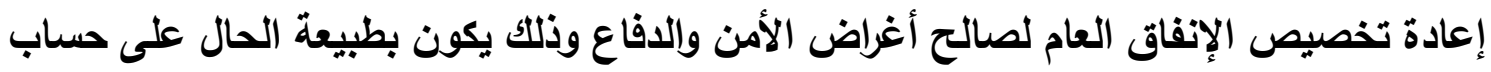
الأغراض التنموية والإنتاجية (Gaibulloev \& Sandler, 2009)، وهو ما يؤثر سلباً على لطي إمكانيات المجتمع الإنتاجية وفرص النمو.

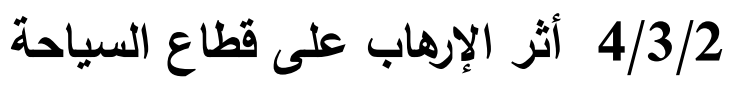
إن قطاع السياحة هو أكثر القطاعات حساسية تجاه الحوادث الإرهابية، لذا فإن كثيراً من الإنه

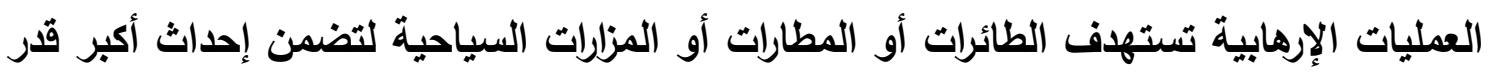

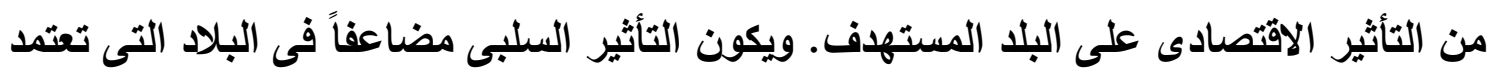
بشكل كبير على قطاع السياحة فى توليد الناتج أو فى التوظيف أو فى توفير العملة الأجنبية

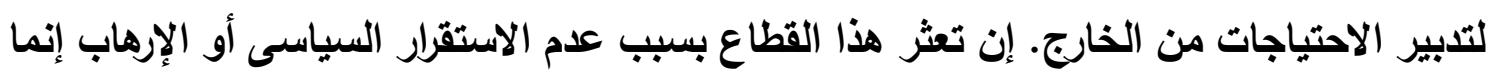
يكبد الاقتصاد خسائر كبرى تتمثل فى خسارة العاملين فى هذا القطاع لوظائفهم وفى خسارة جزيء

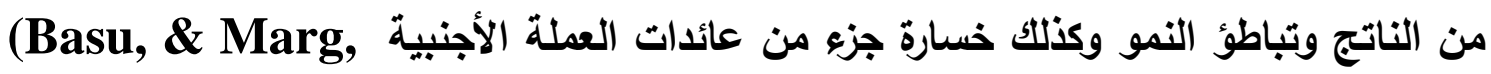

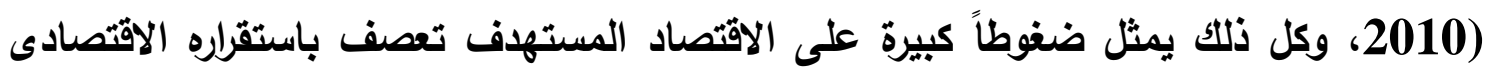
وتصيبه بالعجز المالى الا(خلى والخارجى. 3- الإرهاب والنمو الاقتصادى في الحئ الحالة المصرية

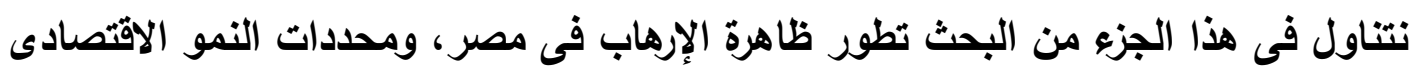
فى الحالة المصرية، وذلك تمهيداً لتقدير أثز الإرهاب على النمو فى الجزيء الأخير من الإراسة. 1/3 تطور ظاهرة الإرهاب فى مصر فئه

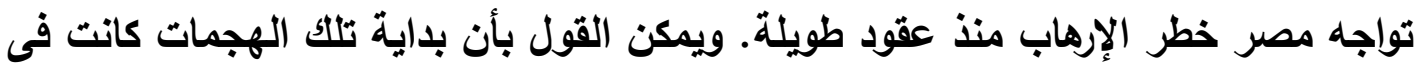

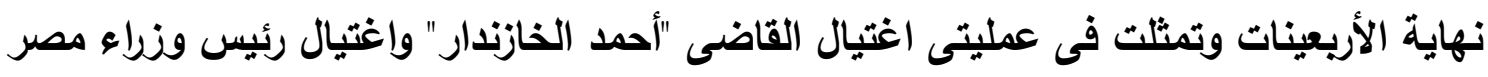

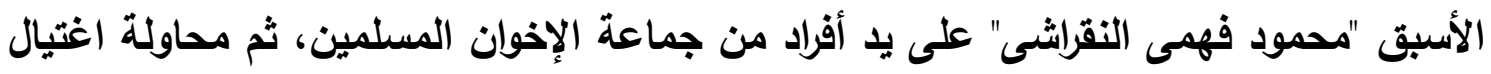

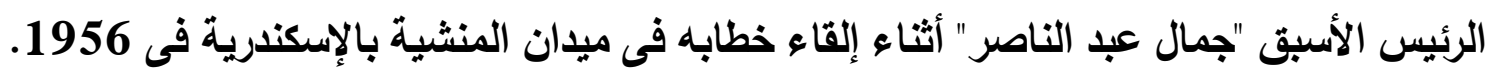

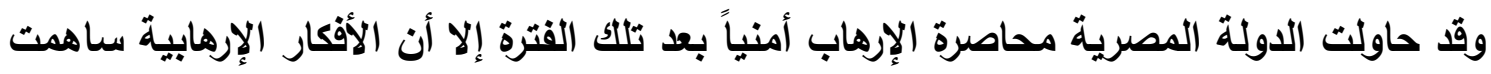

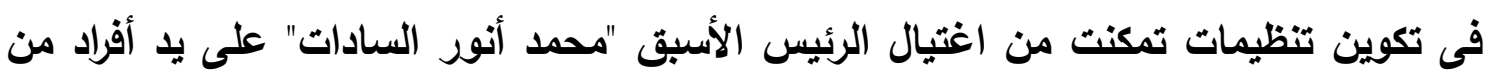

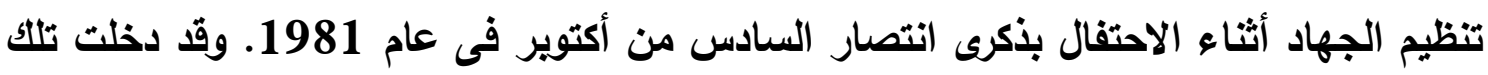

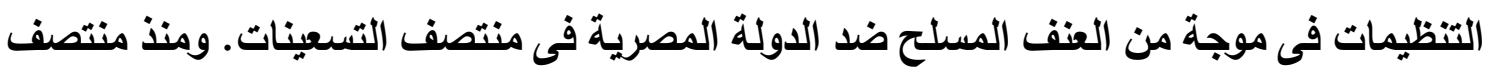

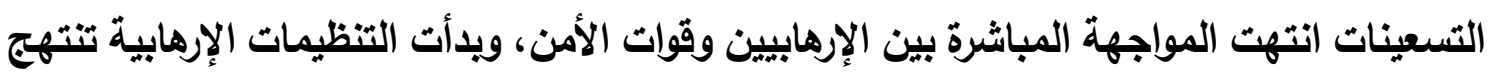
أسلوب التفيرات المتزامنة التى تستهدف المناطق السياحية فى سيناء مثل طابا ونويبع 2004، 
وطابا 2005، ودهب 2006. وقد مرت مصر كما يبين الثكل رقم (1) بفترة من الهدوء وتوققت

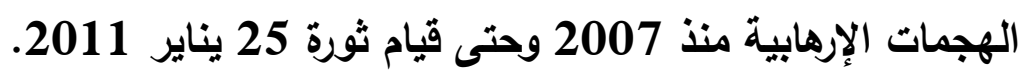

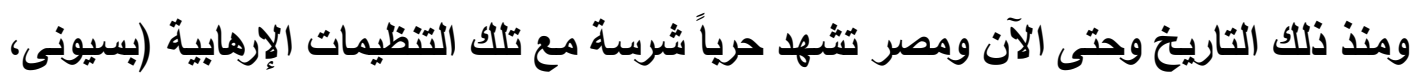
2019)، فقد شهر عام 2011 عمليات إرهابية عدة تمركزت في شمال سيناء، وتركزت على ولى تفجير خطوط الغاز بسيناء، والهجوم على فندق طابا وهجمات متعددة على قوات الثرطة، وأسفرت

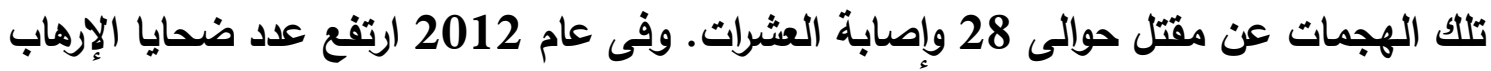
إلى 44 قتيلاً وعشرات المصابين، ووقعت أكثر العمليات الإرهابية عنفاً فى هذا العام العام بمقتل 16

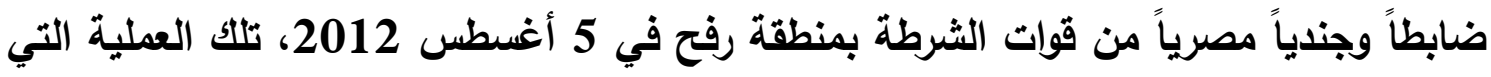
تعتبر نقطة تحول في المشهر السياسي والأمني المصرى.

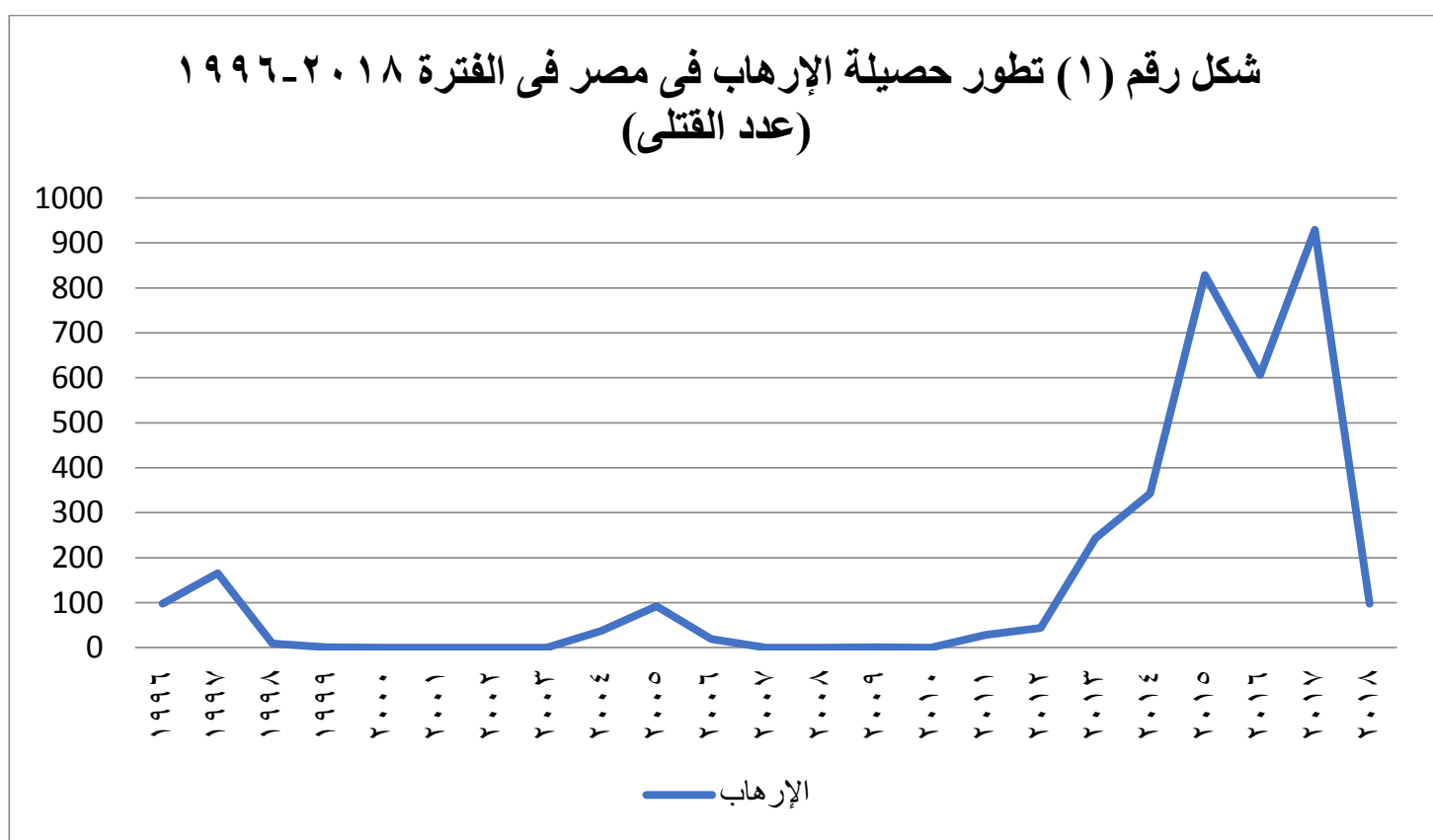

المصدر : بيانات الجدول رقم (1) فى الملحق الإحصائى.

ويعد قيام ثورة 30 يونيو وعزل الرئيس الأسبق "محمد مرسى" تصاعدت معدلات العمليات

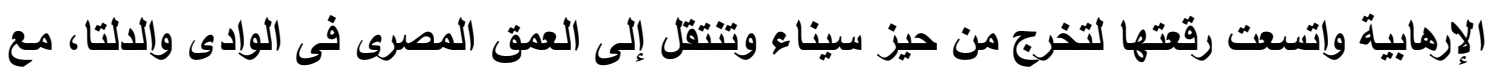

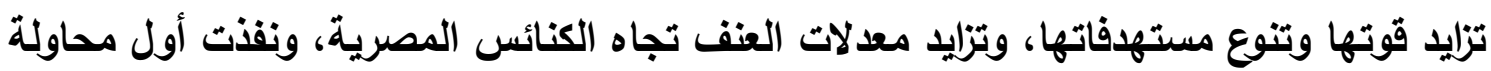

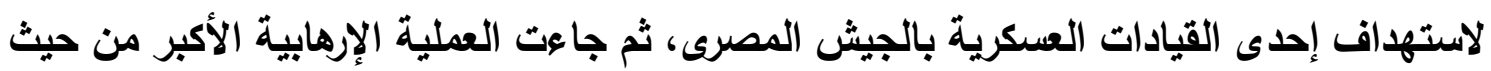

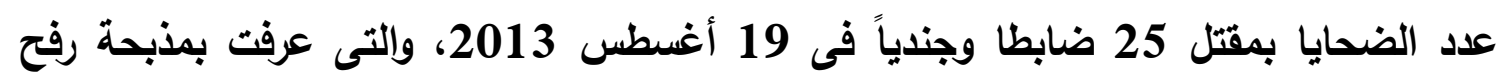
الثانية، وزاد عدد الضحايا فى هذا العام إلى 243 ومئات الجرحى. 
وفى خلال الفترة من 2014 وحتى 2017 كانت ذروة المواجهة مع الإرهاب (الثكل رقم 2)، واتسمت تلك الفترة بخصائص وأثثكال مختلفة من العمليات الإرهابية، فعلى الرغم من استمرار تصدّر محافظة شمال سيناء كأعلى محافظات الجمهورية التي تقع بها عمليات إرهابية، وأيضاً

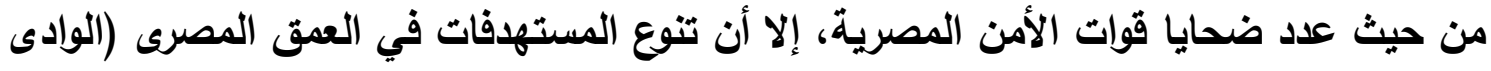

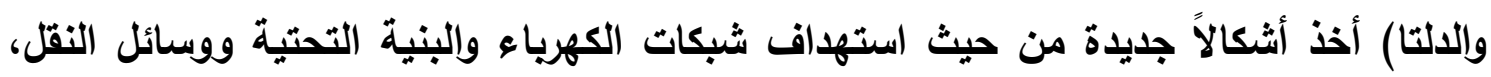

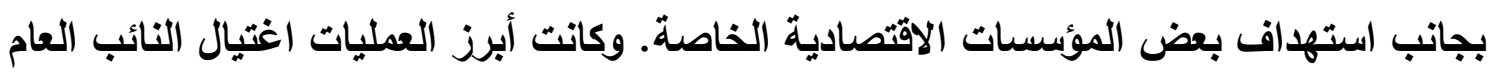

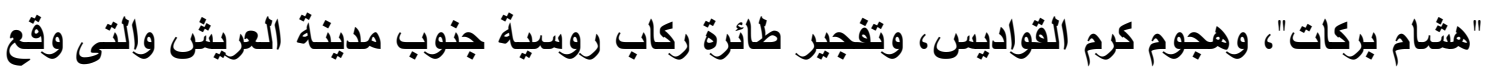

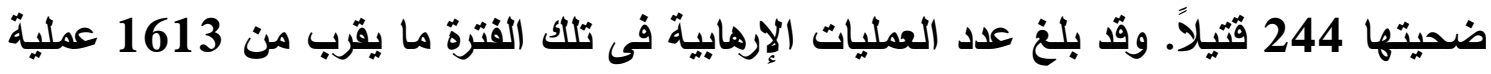

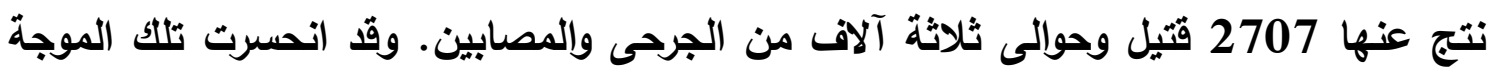

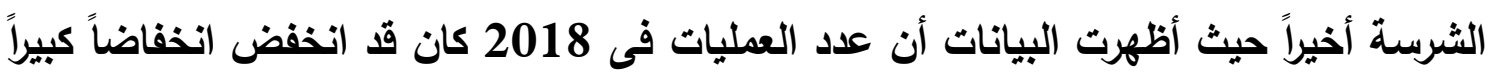
ليصل إلى 55 عملية نتج عنها حوالى 98 قتيل و 119 جريح ومصاب.

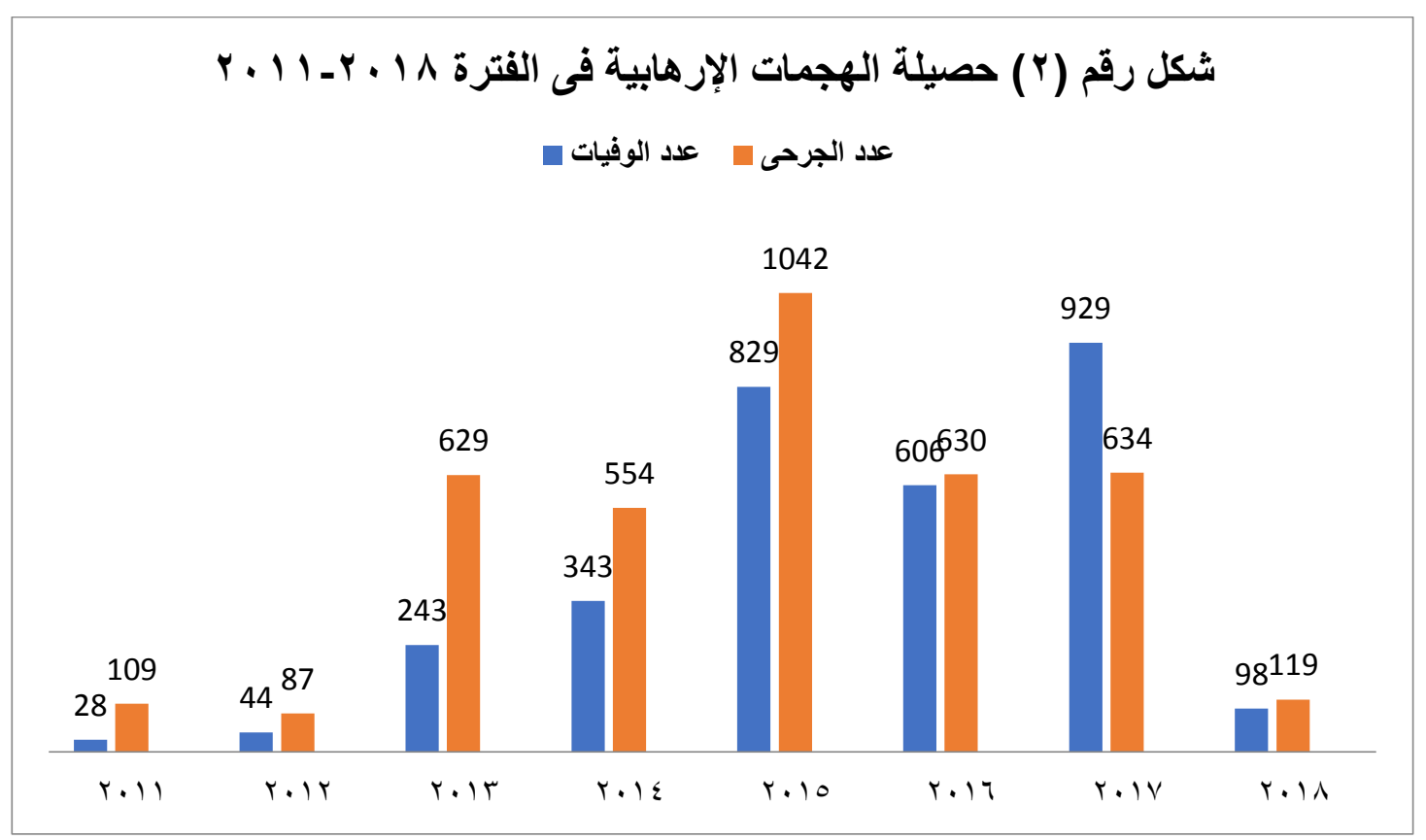

المصدر: بيانات الجدول رقم (1) فى الملحق الإحصائى.

2/3 محددات النمو الاقتصادى فى الحالة المصرية

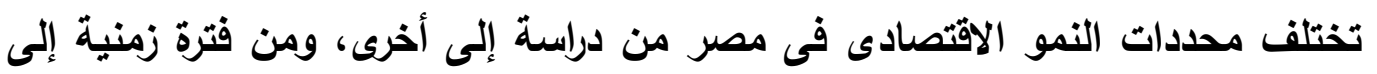
أخرى. فقد خلصت إحدى الدراسات التطبيقية التى تناولت الفترة 1961-2003 إلى أن الإنفاق الحكومى والائتمان المتاح للقطاع الخاص والنمو فى دول OECD كانت عوامل هامة فى إنجاز 
النمو فى مصر، بينما كان أهم معوقات النمو فى الفترة المذكورة هو النقص فى كفاءة الوساطة المالية (Dobronogov \& Iqbal, 2005).

وخلصت دراسة أخرى تناولت الفترة 1970-2006، أن المتغيرات التى تؤيثر إيجابياً على

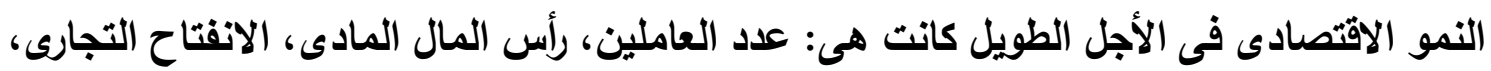

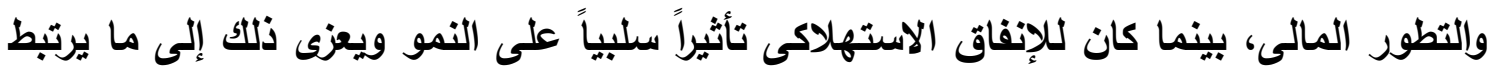

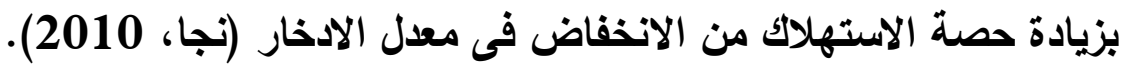
وفى دراسة ثالثة نتاولت الفترة 1985-2007، كثفت نتائج التقاير عن التأثير الإيجابى

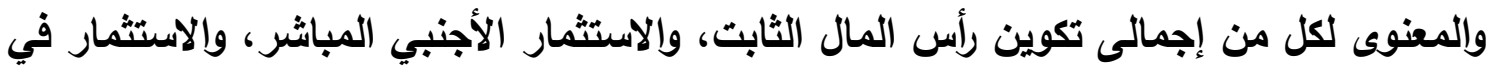

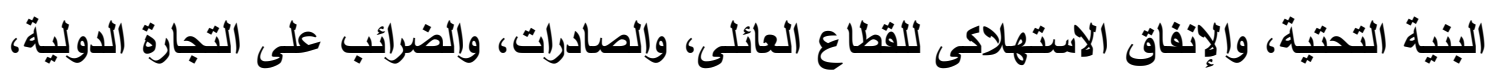

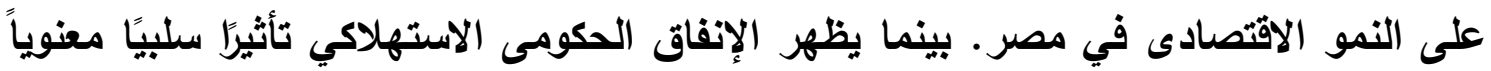
على النمو الاقتصادى فى الفترة المذكورة (Hammam, 2010). كما أوضحت دراسة أخرى تناولت الفترة 1990-2008 الأثر الكبير لتدفقات رؤوس التهاد الأموال، ويخاصة الاستثمار الأجنبى المباشر ، فى تحقيق الاستقرار المالى وتوفير الظروف الماتِ المواتية

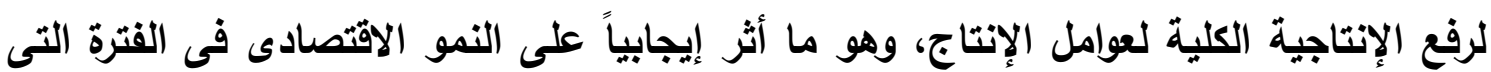
تناولتها الاراسة (Herrera \& Others, 2010). كما أظهرت دراسة أخيرة طبقت على الفترة 1990-2015 أنه فى الأجل القصير تؤدى زيادة

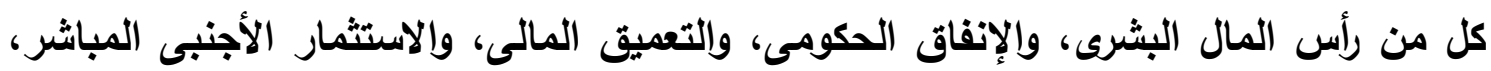

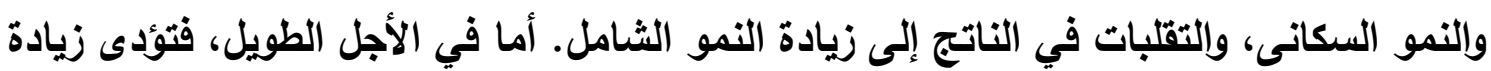

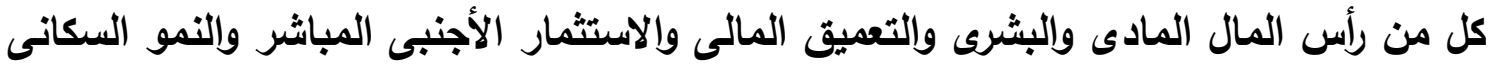

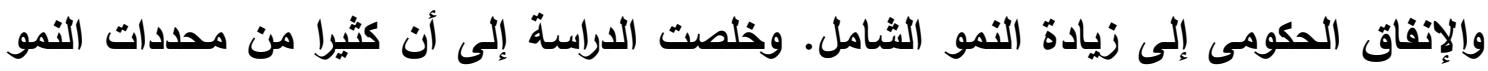

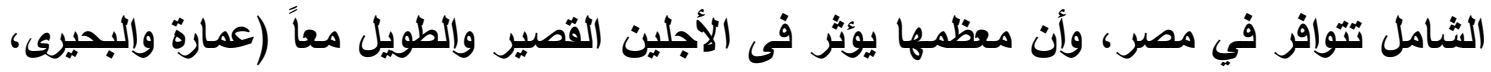
.(2018

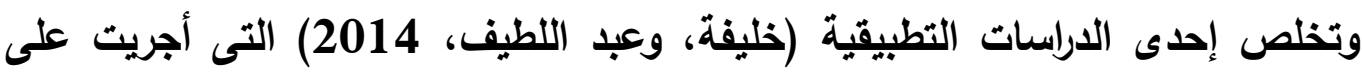

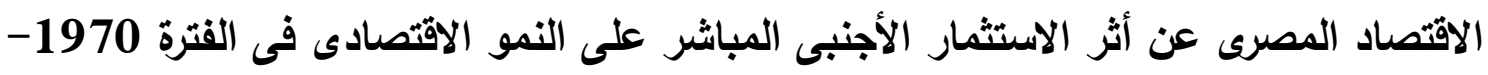

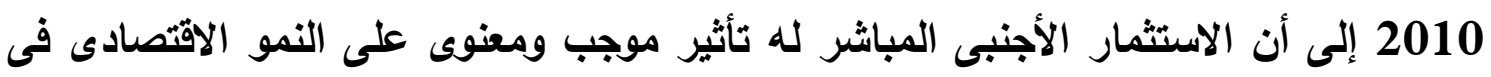

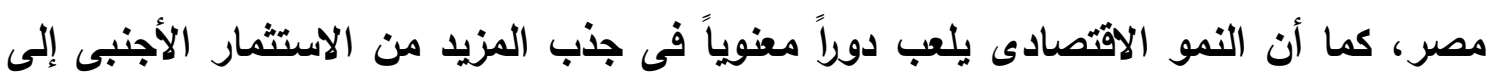
الالاقتصاد المصرى. 
ومما سبق يتبين لنا أن الاستثمار بثقيه المحلى والخارجى وما يتصل به من تسهيلات

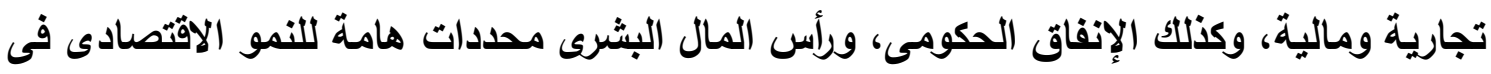

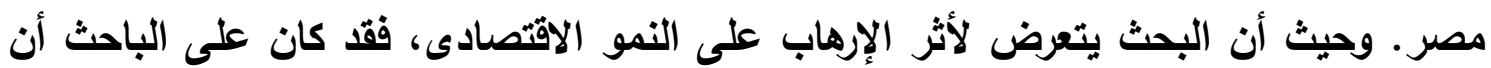

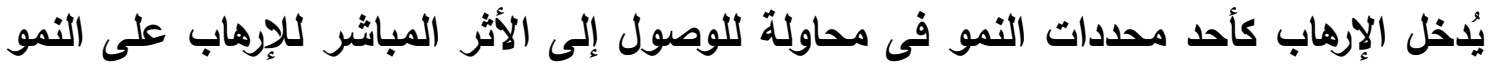

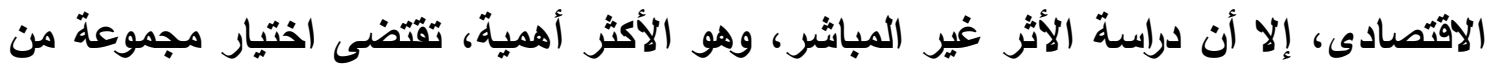

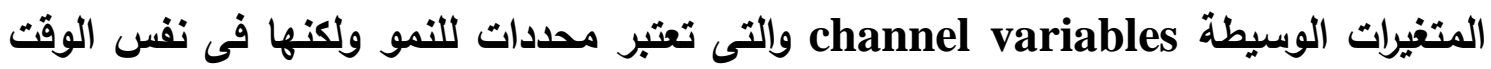
الأكثر تأثراً بالإرهاب كما تقترح النظرية الاقتصادية، ودراسة أثر الإرهاب على كل من تلك المتفيرات

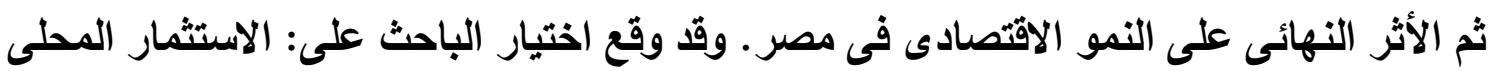

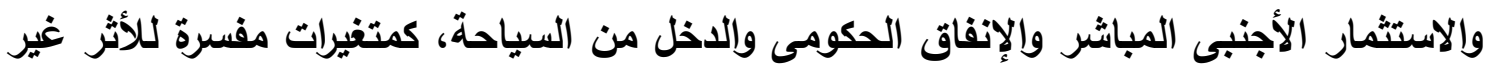

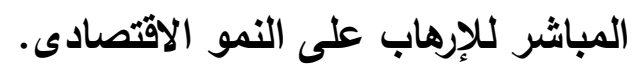

وتؤكد البيانات الواردة فى الجدول رقم (2) فى الملحق الإحصائى وكذلك الشكل رقم (3) هذا لألمان الارتباط الطردى القائم بين كل من الاستثمار المحلى والاستثمار الأجنبى المباثر من ناحية والنمو الاقتصادى فى مصر من ناحية أخرى فى الفترة 1996-2018.

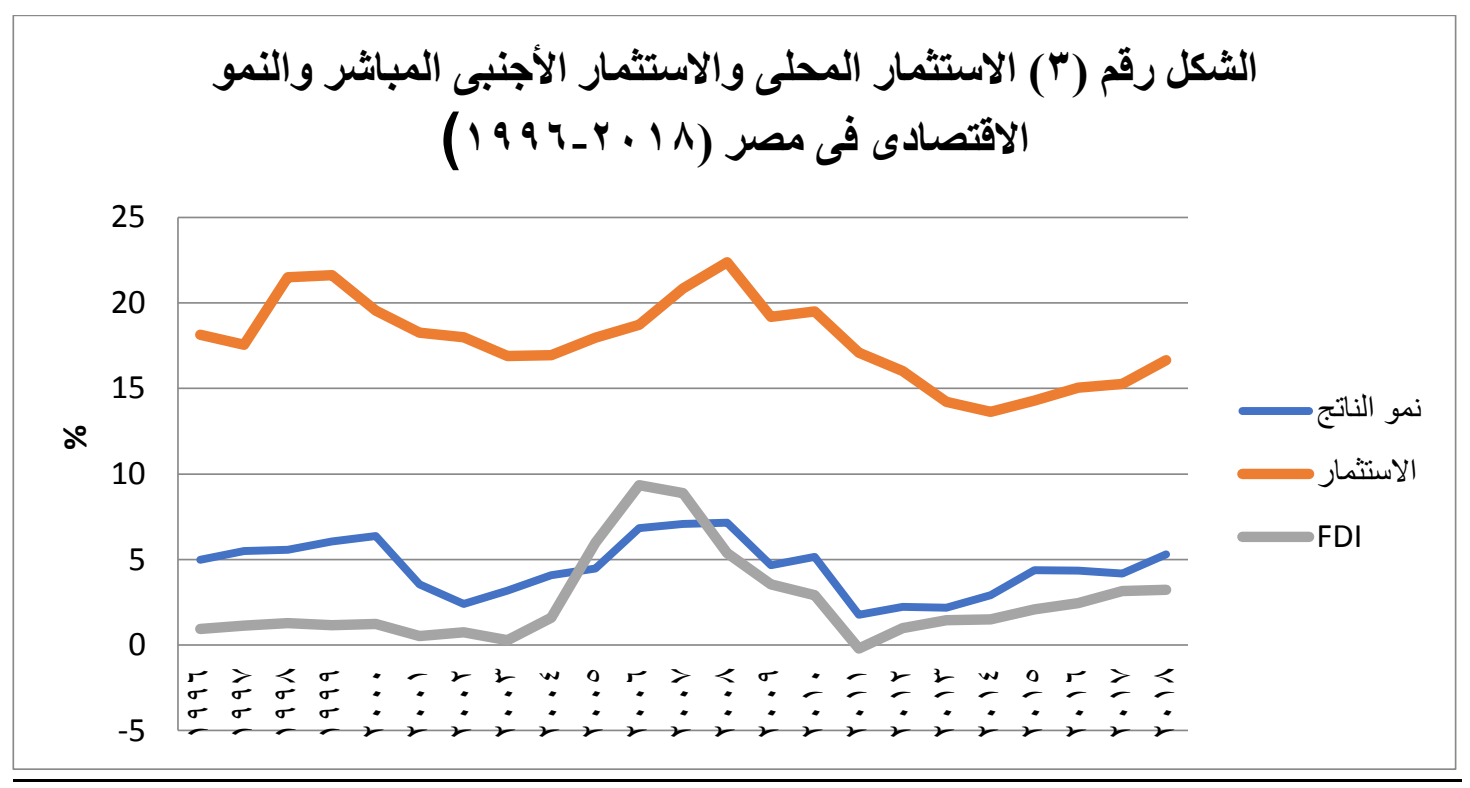

المصدر: بيانات الجدول رقم (2) فى الملحق الإحصائى.

فبالنسبة للاستثمار الإجمالى نجد أن الاقتصاد كان يحقق نمواً ملحوظاً (6\% تقريباً) فى عام 1999 حيث كان الاستثمار المحلى يساوى حوالى 21\% من الناتج المحلى الإجمالى، ثم تناقص الاستثمار المحلى بثكل كبير حتى وصل إلى 16.8\% عام 2003 وهو ما أثر على معدل نمو الناتج حيث انخفض ليصل إلى 3.2\%. 
فلما تعافى الاستثمار ووصل إلى أقصى مستوى له خلال فترة البحث (22.3\% فى عام

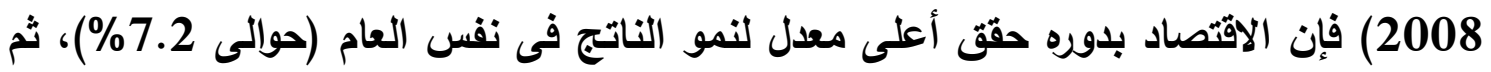

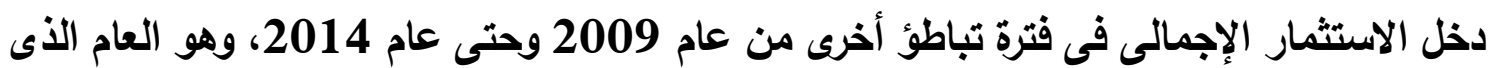
حقى فيه الاقتصاد أدنى مستوى للاستثمار المحلى (13.6\%) وارتبط هذا بتناقص معدل نمو

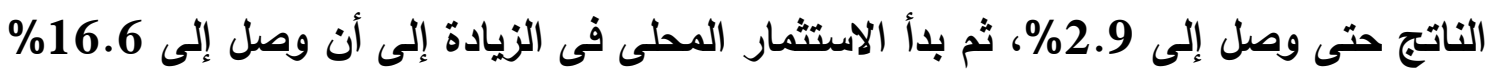

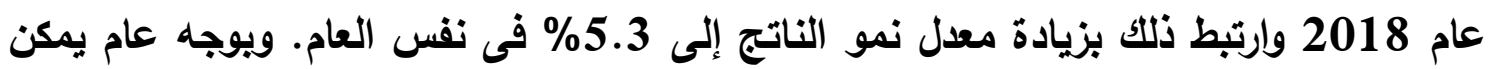

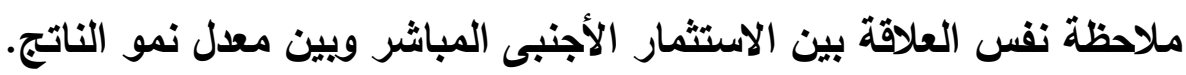

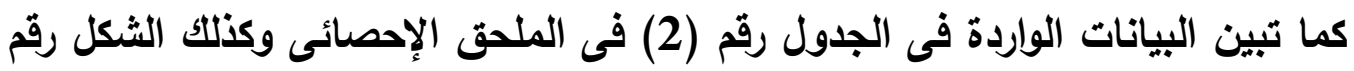
(4) وجود ارتباط طردى بين الدخل من السياحة (ويقاس بناتج قطاع السياحة كنسبة من الناتج

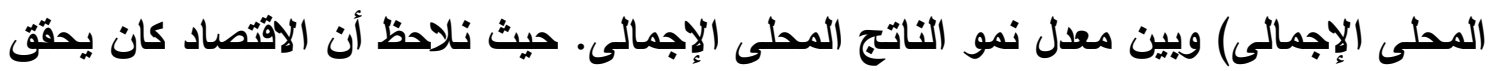

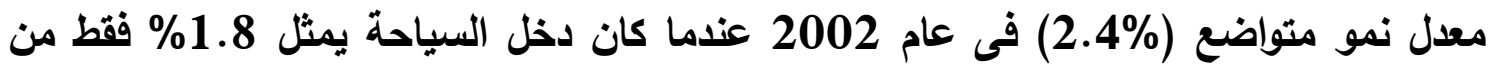

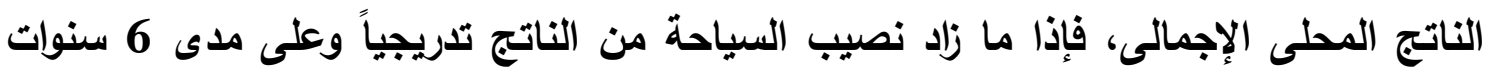

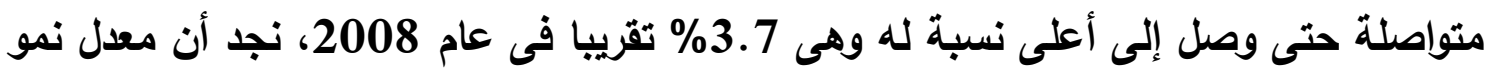

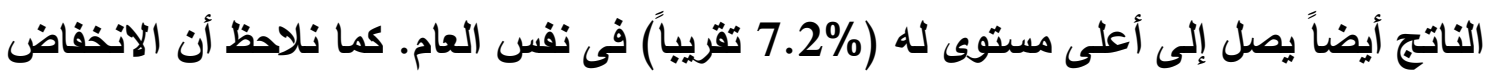

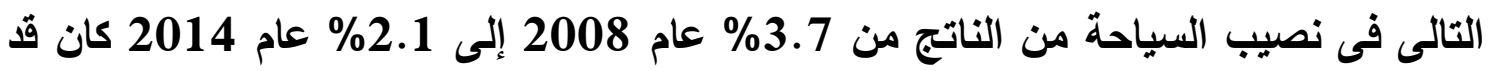

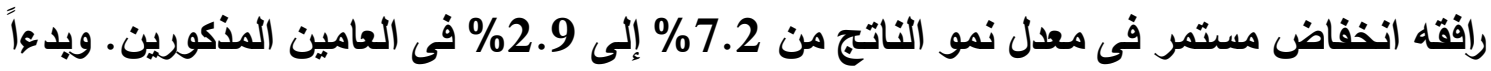
من عام 2017 نلاحظ ارتفاع النصيب النسبى لقطاع السياحة من الناتج وارتفاع معدل نمو الناتج كنلك.

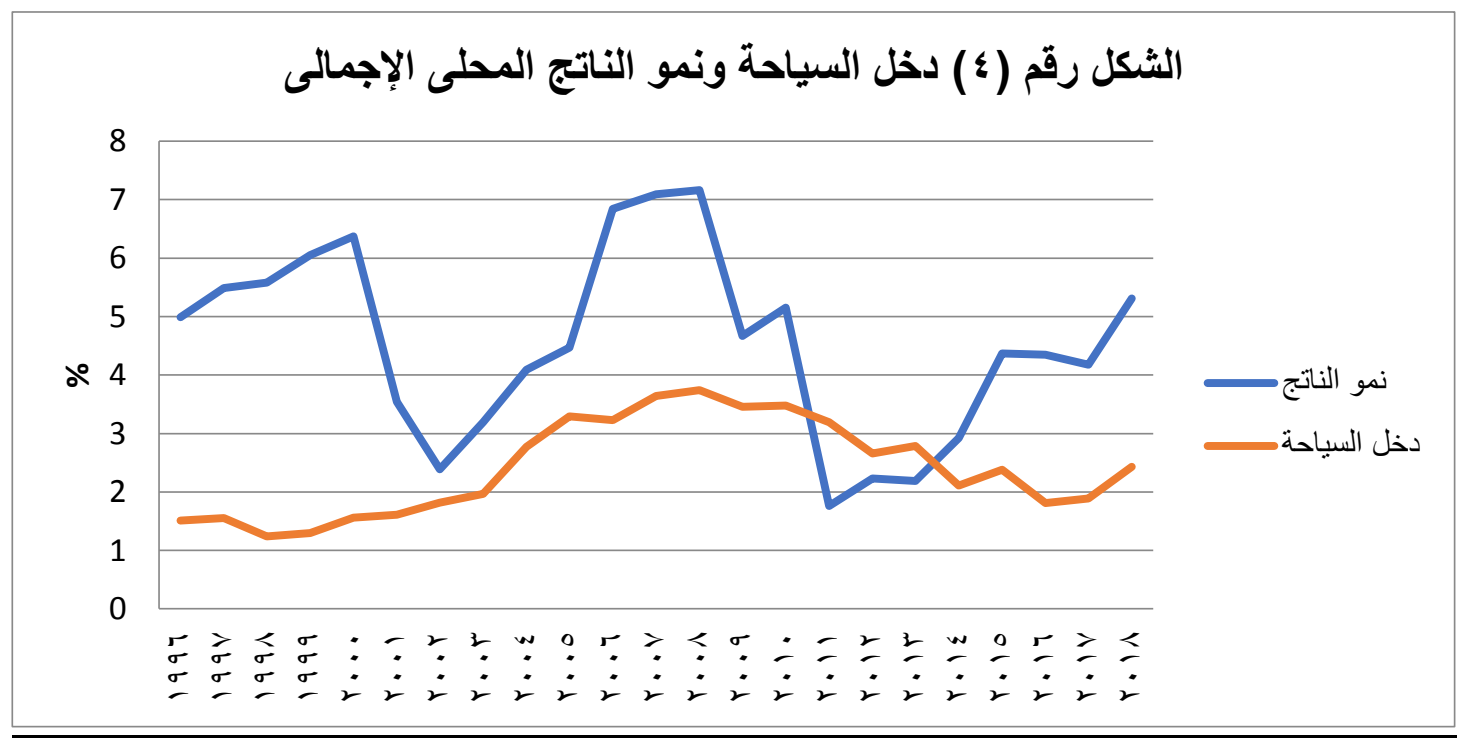

المصدر : بيانات الجدول رقم (2) فى الملدق الإحصائى. 
4- تقدير أثثر الإرهاب على النمو الاقتصادى فى مصر فى الفترة 1996-2018

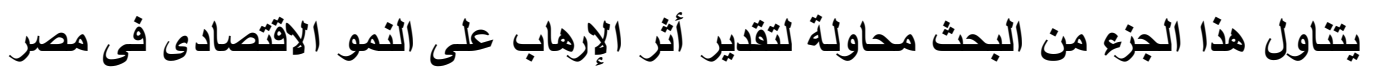

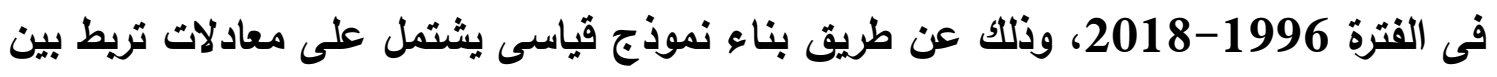

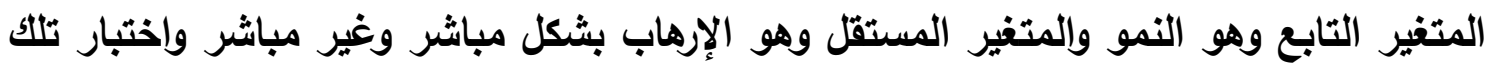
العلاقات باستخام تحليل السلاسل الزمنية واستخلاص النتائج.

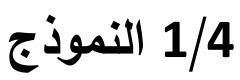

لتقير أثر الإرهاب على النمو الاقتصادى بشكل مباشر ، نستخدم المعادلة (1):

$G R W_{t}=\alpha_{1}+\alpha_{2} I N V_{t}+\alpha_{3} F D I_{t}+\alpha_{4} G O V_{t}+\alpha_{5} T O R_{t}+\alpha_{6} H C_{t}+\alpha_{7} T E R_{t}+\varepsilon_{t}$

\section{حيث:}

= معدل نمو الناتج الحقيقى $=$ GRW

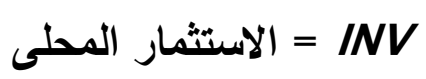

FOV

GOV

TOR

= رأس المال البشرى

الإرهاب = TER

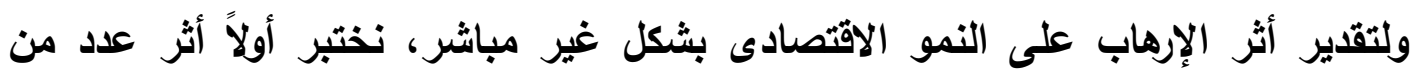

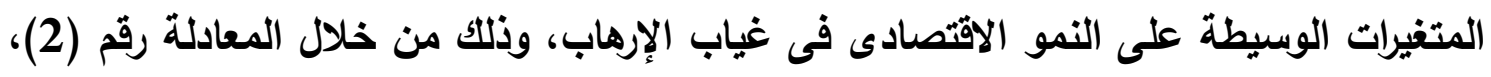

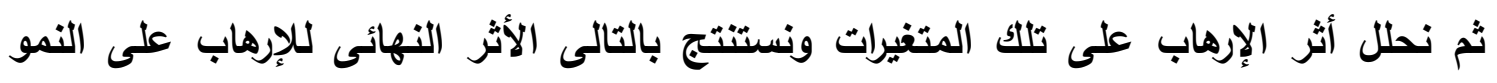

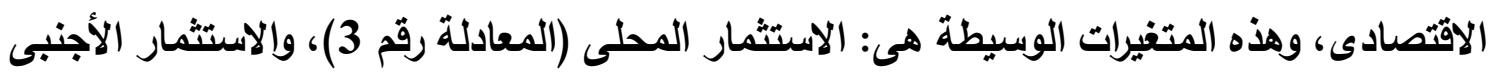
المباثر (المعادلة رقم 4) والإنفاق الحكومى (المعادلة رقم 5) والدخل من السياحة (المعادلة رقم

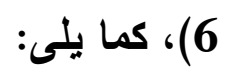

$$
\begin{aligned}
& G R W_{t}=\beta_{1}+\beta_{2} I N V_{t}+\beta_{3} F D I_{t}+\beta_{4} G O V_{t}+\beta_{5} T^{T O R_{t}}+\beta_{6} H C_{t}+v_{t} \\
& I N V_{t}=\gamma_{1}+\gamma_{2} G D P_{t}+\gamma_{3} C P_{t}+\gamma_{4} E R_{t}+\gamma_{5} \mathrm{FDI}_{\mathrm{t}}+\gamma_{6} \mathrm{TER}_{\mathrm{t}}+\mu_{t} \\
& F D I_{t}=\lambda_{1}+\lambda_{2} G D P_{t}+\lambda_{3} T O_{t}+\lambda_{4} E R_{t}+\lambda_{5} I N V_{t}+\lambda_{6} T R_{t}+\omega_{t} \\
& \operatorname{GOV}_{t}=\rho_{1}+\rho_{2} G D P_{t}+\rho_{3} F D_{t}+\rho_{4} A I D_{t}+\rho_{5} T O_{t}+\rho_{6} T E R_{t}+v_{t}
\end{aligned}
$$




$$
\operatorname{TOR}_{t}=\pi_{1}++\pi_{2} \text { FPER }_{t}+\pi_{3} E R_{t}+\pi_{3} H C_{t}+\pi_{4} \mathrm{INVT}_{\mathrm{t}}+\pi_{5} \mathrm{TER}_{t}+\zeta_{t}
$$

$$
\begin{aligned}
& \text { حيث: } \\
& \text { GDP } \\
& \text { الائتمان المتاح للقطاع الخاص الاجمالع = CP } \\
& \text { ER } \\
& \text { TO = الانفتاح التجارى الترو }
\end{aligned}
$$

= FPER

INVT

2/4 البيانات والمصادر

تثثمل البيانات الفترة الممتدة من 1996 إلى 2018. ويحسب كل من الاستثمار المحلى

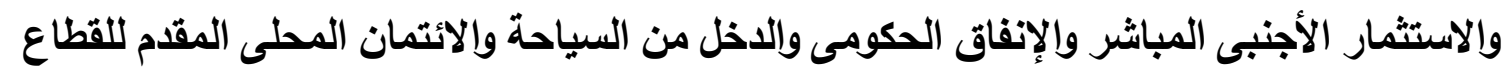

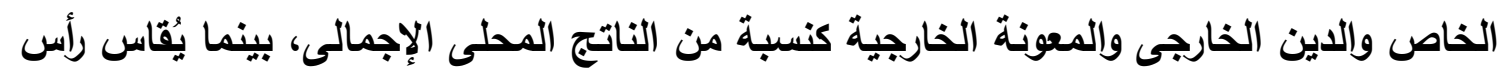

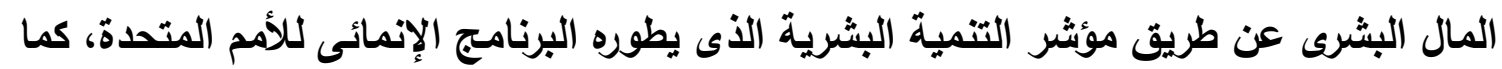

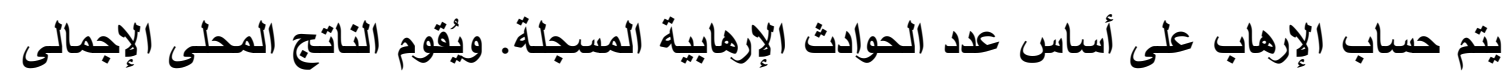

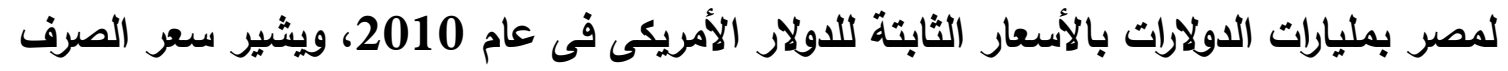

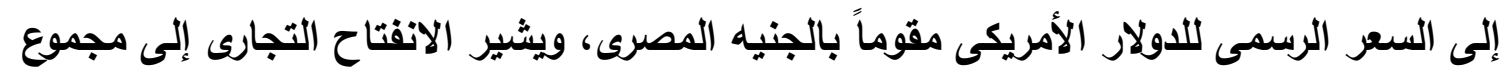

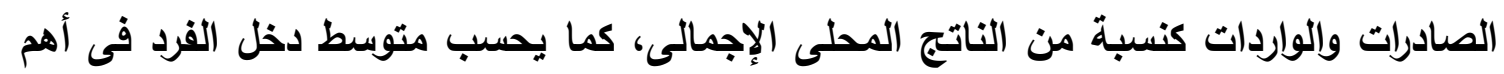

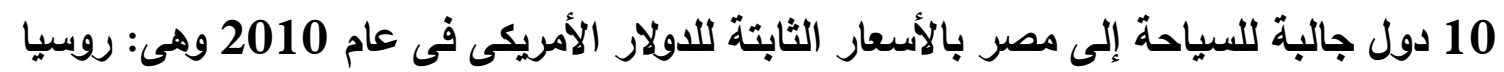

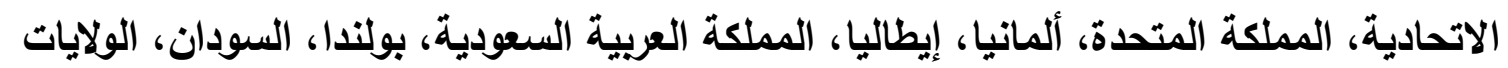

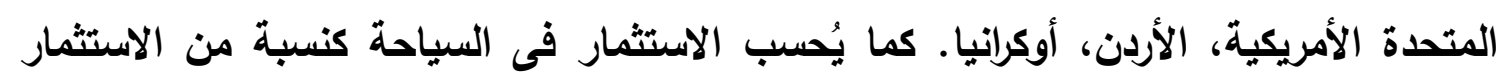
المحلى الإجمالى. - الإهريه. وقد تم الوصول إلى المطومات الخاصة بالإرهاب عن طريق بيانات القاعدة الدولية للإرهاب

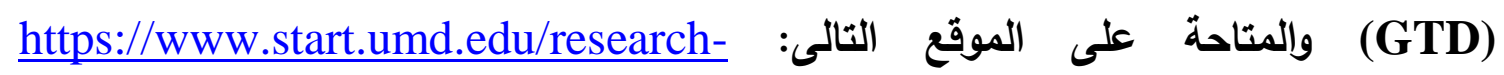
projects/global-terrorism-database-gtd

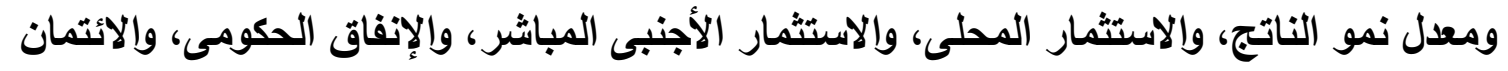

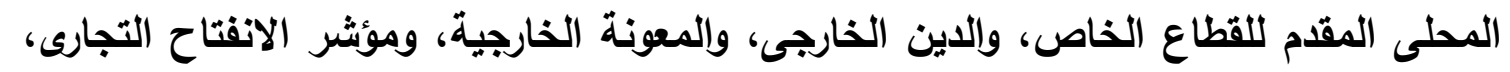

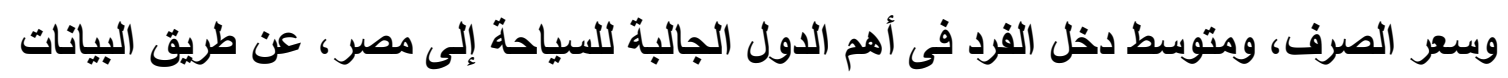

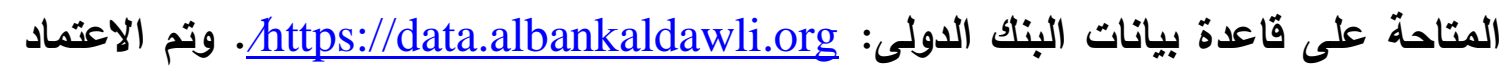


على بيانات وزارة التخطيط والتنمية الاقتصادية: /https://mped.gov.eg فيما يخص بيانات

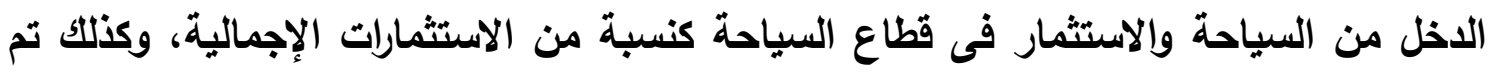

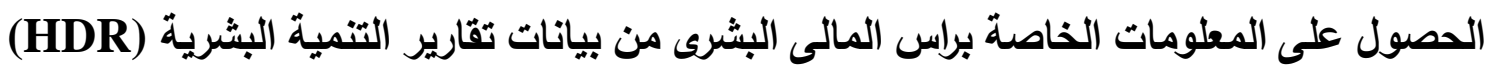

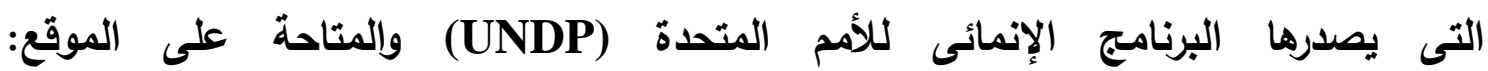
.http://www.hdr.undp.org/ 3/4 تحليل النتائج

1/3/4 تحليل سكون السلاسل الزمنية باستخدام اختبار ديكى- فولر (ADF): ابتكر (Dickey \& Fuller, 1979, 1980) طريقة لاختبار عدم استقرار السلسلة الزمنية وهو مرادف لاختبار وجود جذر الوحدة (حسن وشومان، 2013). والاختبار مبني على النى

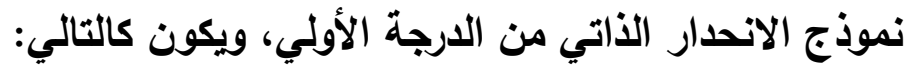

$$
y_{t}=\emptyset y_{t-1}+u_{t}
$$

بحيث يتم اختبار ماذا كانت ض هساوي 1 ومن هنا جذر الوحدة فرضية العدم

$$
H_{1}: \emptyset<1 \text { والفرضية البليلة } H_{0}: \emptyset=1
$$

وهناك شكل آخر للاختبار يمكن العصول عليه بطرح

$$
y_{t}-y_{t-1}=(\emptyset-1) y_{t_{-1}}+u_{t}
$$

حيث تمثل

$$
\Delta y_{t}=(\emptyset-1) y_{t-1}+u_{t}
$$

والفرضية البذيلة $H_{0}: \gamma=0$ مساراً عشوائياً.

واقترح Dickey \& Fuller معادلتين للانحدار يمكن أن تستخدم لاختبار جذر الوحدة

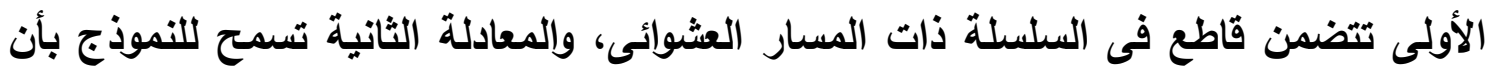
يتضمن متجة زمنى غير عشوائى. وإختبار ADF للاستقرار هو t للمعامل لمتباطئة المتغير التابع Dickey \& Fuller

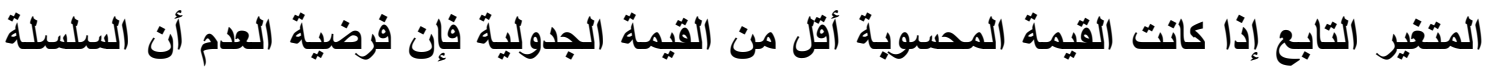
الزمنية غير مستقرة يتم قبولها ونستتتج أنها غير مستقرة. 
ويتضح من بيانات الجدول (1) أنه باستخدام اختبار ADF، وياستخدام البرنامج الإحصائى

E-views

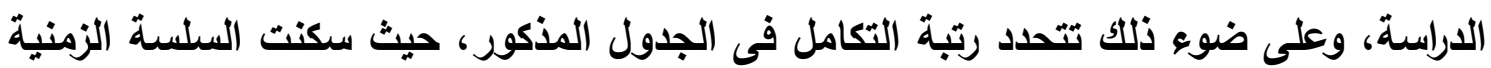

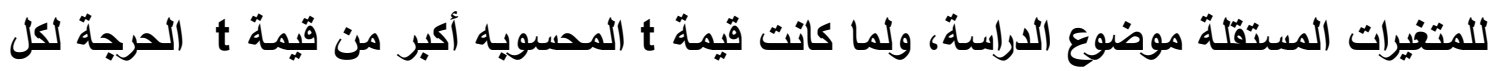
المتغيرات الداخلة فى النماذج المستخدمة فإنه يتم رفض الفرض الصفرى بوجود جذر الوحدة وقبول الفرض البديل، ويذلك تعتبر السلسة الزمنية ساكنة. جدول (1) نتائج اختبار استقرار متغيرات نماذج الدراسة للتأكد من سكون السلاسل الزمنية

باستخدام الاختبارات المختلفة لجذر الوحدة Unit Root Test للفترة (1996 - 2018 )

\begin{tabular}{|c|c|c|c|c|c|c|}
\hline \multirow{2}{*}{ Variable } & \multicolumn{2}{|c|}{ Level } & \multicolumn{2}{c|}{1 St Deference } & \multicolumn{2}{c|}{2 St Deference } \\
\cline { 2 - 7 } & $\begin{array}{c}\text { ADF } \\
\text { Statistics }\end{array}$ & Result & $\begin{array}{c}\text { ADF } \\
\text { Statistics }\end{array}$ & Result & $\begin{array}{c}\text { ADF } \\
\text { Statistics }\end{array}$ & Result \\
\hline GRW & -3.198 & NON & -4.24 & Statistics & - & - \\
\hline INV & -1.508 & NON & -3.800 & Statistics & - & - \\
\hline FDI & -2.853 & NON & -2.756 & NON & -4.565 & Statistics \\
\hline GOV & -2.307 & NON & -7.223 & Statistics & - & - \\
\hline TOR & -3.519 & NON & -3.912 & Statistics & - & - \\
\hline HC & -3.243 & NON & -15.64 & Statistics & - & - \\
\hline GDP & 2.120 & NON & -2.245 & NON & -4.301 & Statistics \\
\hline CP & -0.226 & NON & -2.98 & NON & -7.509 & Statistics \\
\hline ER & 1.300 & NON & -3.58 & NON & -6.140 & Statistics \\
\hline TO & -1.810 & NON & -3.39 & NON & -4.914 & Statistics \\
\hline FD & -1.572 & NON & -2.81 & NON & 5.185 & Statistics \\
\hline AID & -3.030 & NON & -4.83 & Statistics & - & - \\
\hline FPER & -1.307 & NON & -4.04 & Statistics & - & - \\
\hline INVT & -0.391 & NON & -14.33 & Statistics & - & - \\
\hline
\end{tabular}

المصدر : من إعداد الباحث اعتماداً على مخرجات البرنامج الإحصائى (E-Views)

2/3/4 الأثر المباشر للإرهاب على النمو الاقتصادى

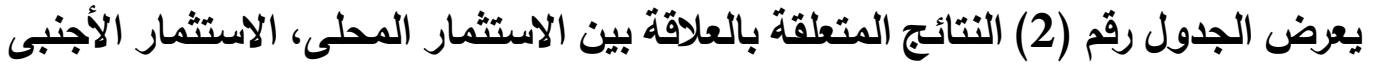
المباشر ، الإنفاق الحكومى، الاخل من السياحة، رأس المال البثرى، والإرهاب، كتفيرات مستقلة، 
والمتغير التابع وهو معدل نمو الناتج الحقيقى، وذلك خلال الفترة (2018-1996) وذلك باستخدام أسلوب الانحدار المتعدد فى الصورة الخطية. جدول (2) الأثر المباشر للإرهاب على معدل النمو الاقتصادى

\begin{tabular}{|c|c|c|c|c|}
\hline \multicolumn{5}{|c|}{ Dependent Variable: GRW } \\
\hline \multicolumn{5}{|c|}{ Method: Least Squares } \\
\hline \multicolumn{5}{|c|}{ Sample: 19962018} \\
\hline \multicolumn{5}{|c|}{ Included observations: 23} \\
\hline Variable & Coefficient & Std. Error & t-Statistic & Prob. \\
\hline C & -4.639584 & 6.254114 & -0.741845 & 0.4689 \\
\hline INV & 0.373220 & 0.118062 & $3.161229^{\star \star}$ & 0.0061 \\
\hline FDI & 0.419446 & 0.110758 & $3.787047^{\star \star}$ & 0.0016 \\
\hline GOV & 0.005325 & 0.036309 & 0.146654 & 0.8852 \\
\hline TOR & 0.885890 & 0.420432 & $2.107095^{\star}$ & 0.0512 \\
\hline $\mathrm{HC}$ & 5.437397 & 8.028303 & 0.677279 & 0.5079 \\
\hline TER & -0.002084 & 0.001192 & $-1.748562^{*}$ & 0.0995 \\
\hline R-squared & 0.813645 & \multicolumn{2}{|c|}{ Mean dependent var } & 4.358696 \\
\hline Adjusted R-squared & 0.743763 & \multicolumn{2}{|c|}{ S.D. dependent var } & 1.822369 \\
\hline S.E. of regression & 0.922482 & \multicolumn{2}{|c|}{ Akaike info criterion } & 2.922292 \\
\hline Sum squared resid & 13.61556 & \multicolumn{2}{|c|}{ Schwarz criterion } & 3.267877 \\
\hline Log likelihood & -26.60635 & \multicolumn{2}{|c|}{ F-statistic } & 11.64298 \\
\hline Durbin-Watson stat & 1.980078 & \multicolumn{2}{|c|}{ Prob(F-statistic) } & 0.000046 \\
\hline
\end{tabular}

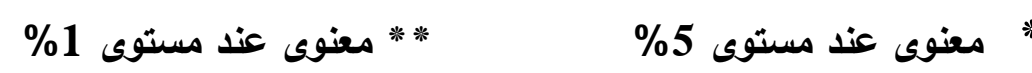

المصدر : من إعداد الباحث اعتماداً على مخرجات البرنامج الاحصائى (E-Views)

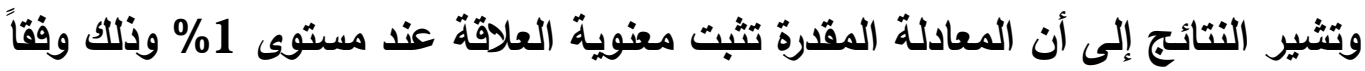
لقيمة ف المحسوية والتى بلغت حوالى 11.64 وهى أكبر من نظيرتها الجدولية عند نفس المستوى من المعنوية، كما تثير قيمة معامل التحديد والذى بلغ حوالى 0.74 إلى أن المتغيرات المستقلة تؤثثر فى معدل نمو الناتج الحقيقى بنسبة 74\%. كما أظهرت النتائج وجود علاقة طردية بين كل كلئ من الاستثمار المحلى، الاستثمار الاجنبى المباشر، الاخل من السياحة كمتغيرات مستقلة والمتغير

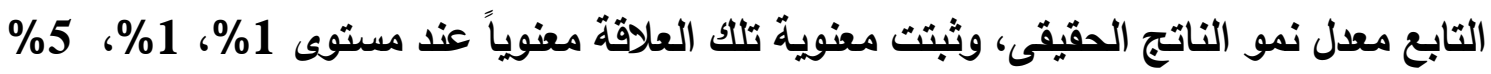


على التوالى. كما أظهرت النتائج وجود علاقة عكسية بين عدد حوادث الإرهاب خلال فترة الدراسة

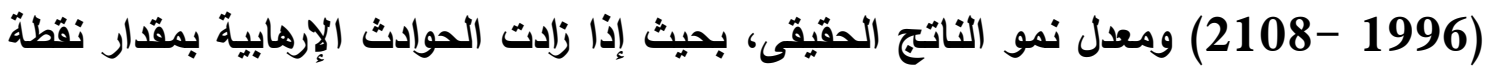
مئوية واحدة انخفض معدل نمو الناتج الحقيقى بمقار 002084 نقطة مئوية، وثبتت معنوية

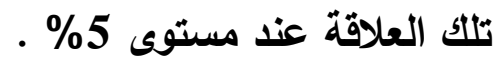
3/3/4 الأثر غير المباشر للإرهاب على النمو الاثتصادى

الخطوة الأولى لتقدير الأثر غير المباشر للإرهاب على النمو هى تحديد أثر المتغيرات الوسيطة على النمو الاقتصادى (المعادلة 2). ويعرض الجدول رقم (3) النتائج المتعلقة بتحليل العلاقة بين الاستثمار المحلى، الاستثمار الأجنبى المباشر، الإنفاق الحكومى، الاخل من السياحة،

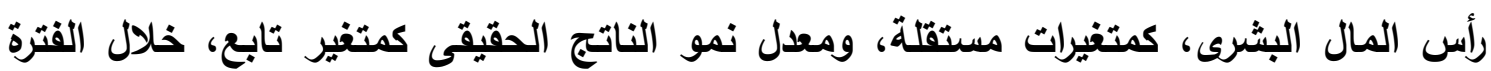
2018-1996، وذلك باستخدام أسلوب الانحدار المتعدد فى الصورة الخطية. جدول (3) أهم العوامل المؤثرة على معدل نمو الناتج الحقيقى

\begin{tabular}{|c|c|c|c|c|}
\hline \multicolumn{5}{|c|}{ Dependent Variable: GRW } \\
\hline \multicolumn{5}{|c|}{ Method: Least Squares } \\
\hline \multicolumn{5}{|c|}{ Included observations: 23} \\
\hline Variable & Coefficient & Std. Error & t-Statistic & Prob. \\
\hline C & -0.604640 & 1.899754 & -0.318273 & 0.7542 \\
\hline INV & 0.330666 & 0.084607 & $3.908254^{\star *}$ & 0.0011 \\
\hline FDI & 0.462841 & 0.106077 & $4.363248^{\star *}$ & 0.0004 \\
\hline GOV & 0.005301 & 0.033029 & 0.160487 & 0.8744 \\
\hline TOR & 0.831241 & 0.337205 & $2.465091^{\star}$ & 0.0246 \\
\hline HC & 0.157537 & 1.240558 & 0.126989 & 0.9004 \\
\hline R-squared & 0.761312 & Mean dependent var & 4.538261 \\
\hline Adjusted R-squared & 0.691109 & S.D. dependent var & 1.602735 \\
\hline S.E. of regression & 0.890767 & Akaike info criterion & 2.825991 \\
\hline Sum squared resid & 13.48893 & Schwarz criterion & 3.122207 \\
\hline Log likelihood & -26.49890 & F-statistic & 10.84452 \\
\hline Durbin-Watson stat & 1.764420 & Prob(F-statistic) & 0.000082 \\
\hline & &
\end{tabular}

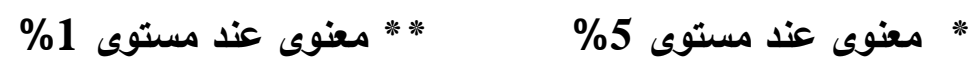
المصدر : من إعداد الباحث اعتمادا على مخرجات البرنامج الاحصائى (E-Views) 
وتثثير النتائج إلى أن المعادلة المقدرة ثبتت معنوية العلاقة عند مستوى 1\%، وذلك وفقاً

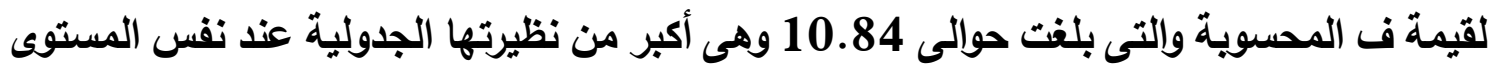
من المعنوية، كما تثير قيمة معامل التحديد والذى بلغ حوالى 0.69 إلى أن المتغيرات المستقلة

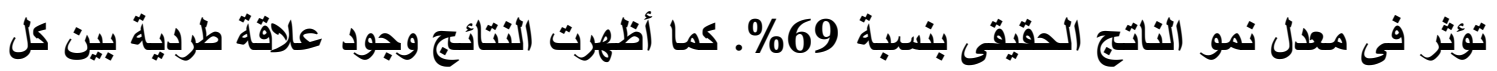

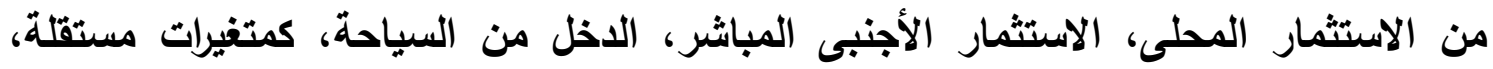

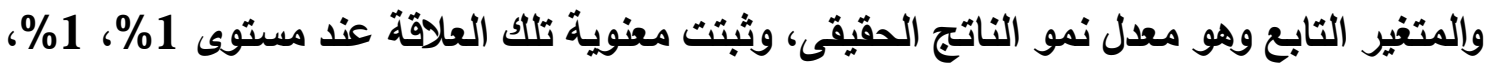
5 5 على التوالى، وهو ما يثير إلى قوة تأثير تلك العوامل الثلاثة في معدل نمو الناتج الحقيقى.

$$
\text { 1/3/3/4 أثر الإرهاب على الاستثمار المحلى }
$$

يعرض الجدول (4) نتائج تحليل العلاقة بين الناتج المحلى الإجمالى، الائتمان المتاح

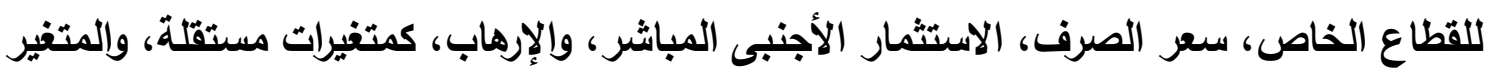
التابع وهو الاستثمار المحلى. وذلك خلال الفترة (2018-1996) وذلكك باستخدام أسلوب الانحدار المتعدد فى الصورة الخطية. وتثثير النتائج إلى أن المعادلة المقدرة ثبتت معنوية العلاقة عند مستوى 1\% وذلتك وفقاً لقيمة ف المحسويه والتى بلغت حوالى 10.09 وهى أكبر من نظيرتها الجدولية عند نفس المستوى

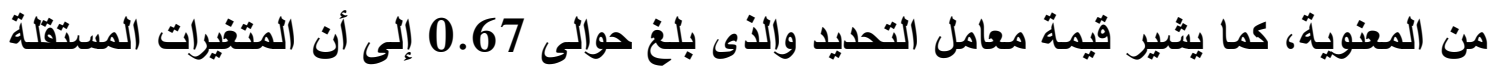

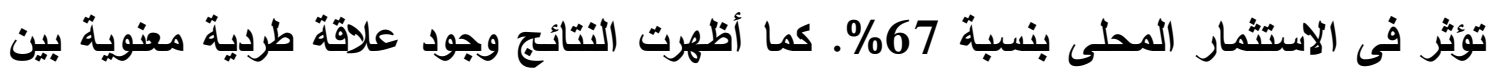
الائتمان المتاح للقطاع الخاص كمتغير مستقل والمتغير التابع وهو الاستثمار المحلى، ووجود

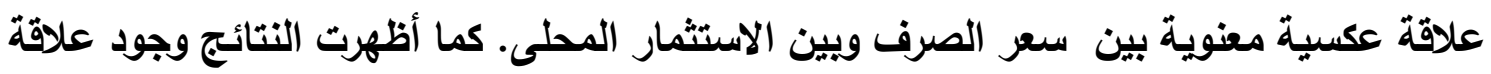

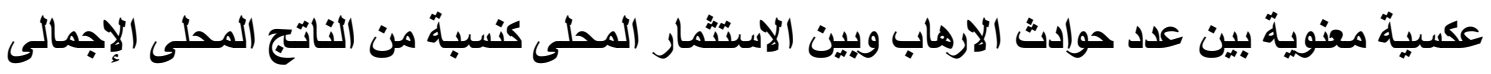

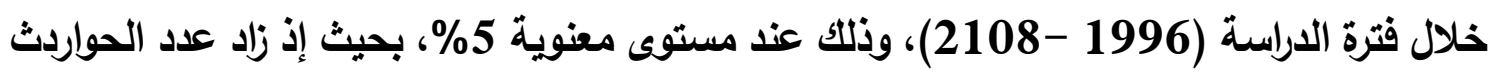
الإرهابية بمقدار نقطة مئوية واحدة انخفض الاستثمار المحلى كنسبة من الناتج المحلى الإجمالى بمقار 0.004877 نقطة مئوية. 
جدول (4) أثر الإرهاب على الاستثمار المحلى

\begin{tabular}{|c|c|c|c|c|}
\hline \multicolumn{5}{|c|}{ Dependent Variable: INV } \\
\hline \multicolumn{5}{|c|}{ Method: Least Squares } \\
\hline \multicolumn{5}{|c|}{ Sample: 19962018} \\
\hline \multicolumn{5}{|c|}{ Included observations: 23} \\
\hline Variable & Coefficient & Std. Error & t-Statistic & Prob. \\
\hline C & 16.13878 & 2.330293 & 6.925643 & 0.0000 \\
\hline GDP & 0.003250 & 0.011732 & 0.277049 & 0.7851 \\
\hline $\mathbf{C P}$ & 0.062005 & 0.028430 & $2.181001^{*}$ & 0.0435 \\
\hline ER & -0.259000 & 0.131323 & $-1.972246^{*}$ & 0.0651 \\
\hline FDI & 0.206967 & 0.134655 & 1.537021 & 0.1427 \\
\hline TER & -0.004877 & 0.002445 & $-1.994502^{\star}$ & 0.0624 \\
\hline R-squared & 0.748113 & \multicolumn{2}{|c|}{ Mean dependent var } & 17.68130 \\
\hline Adjusted R-squared & 0.674029 & \multicolumn{2}{|c|}{ S.D. dependent var } & 2.555670 \\
\hline S.E. of regression & 1.459131 & \multicolumn{2}{|c|}{ Akaike info criterion } & 3.813018 \\
\hline Sum squared resid & 36.19409 & \multicolumn{2}{|c|}{ Schwarz criterion } & 4.109234 \\
\hline Log likelihood & -37.84970 & \multicolumn{2}{|c|}{ F-statistic } & 10.09813 \\
\hline Durbin-Watson stat & 1.006701 & \multicolumn{2}{|c|}{ Prob(F-statistic) } & 0.000127 \\
\hline
\end{tabular}

\% 1 \% معنوى عند مستوى

المصدر : من إعداد الباحث اعتمادا على مخرجات البرنامج الاحصائى (E-Views) 2/3/3/4 أثر الإرهاب على الاستثمار الأجنبى المباشر الباني

يعرض الجدول (5) نتائج تحليل العلاقة بين الناتج المحلى الإجمالى، الانفتاح التجارى، سعر الصرف، الاستثمار المحلى، والإرهاب، كمتغيرات مستقلة، والمتغير التابع وهو الاستثمار الأجنبى المباشر، وذلك خلال الفترة (2018-1996) وياستخدام أسلوب الانحدار المتعدد فى

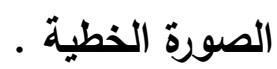

وتثير النتائج إلى أن المعادله المقدرة ثبتت معنوية العلاقة عند مستوى 1\% وذلك وفقاً لقيمة ف المحسوية والتى بلغت حوالى 6.7 وهى أكبر من نظيرتها الجدولية عند نفس المستوى من المعنوية، كما يشير قيمة معامل التحديد والذى بلغ حوالى 0.56 إلى أن المتغيرات المستقلة 
تؤثر فى الاستثمار الأجنبى المباشر بنسبة 56\% . كما أظهرت النتائج وجود علاقة طردية بين

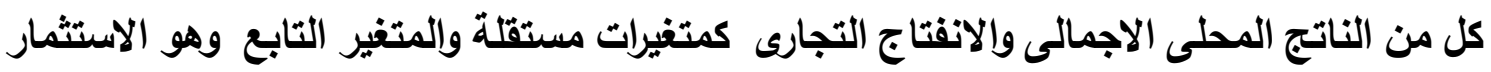

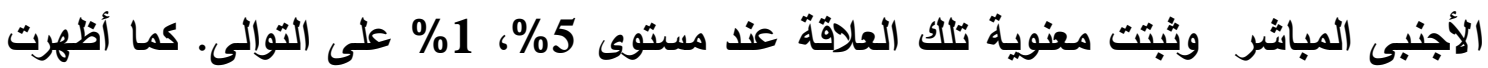
النتائج وجود علاقة عكسية بين عدد الحوادث الإرهابية كمتغير مستقل ويبن الاستثمار الأجنبى

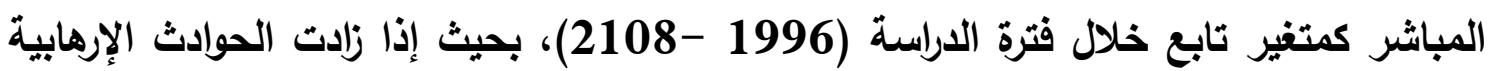
بمقار نقطة مئوية واحدة انخفض الاستثمار الأجنبى المباشر كنسبة من الناتج المحلى الإجمالى بمقار 0.08539 نقطة مئوية، وثبتت معنوية تلك العلاقة العكسية عند مستوى 5\%. جدول (5) العوامل المؤثرة على الاستثمار الاجنبى المباشر

\begin{tabular}{|c|c|c|c|c|}
\hline \multicolumn{5}{|c|}{ Dependent Variable: FDI } \\
\hline \multicolumn{5}{|c|}{ Method: Least Squares } \\
\hline \multicolumn{5}{|c|}{ Sample: 19962018} \\
\hline \multicolumn{5}{|c|}{ Included observations: 23} \\
\hline Variable & Coefficient & Std. Error & t-Statistic & Prob. \\
\hline C & -9.571415 & 4.784511 & -2.000500 & 0.0617 \\
\hline GDP & 0.033312 & 0.016725 & $1.991770^{*}$ & 0.0627 \\
\hline TO & 0.297899 & 0.065724 & $4.532554^{\star \star}$ & 0.0003 \\
\hline ER & 0.191167 & 0.157307 & 1.215252 & 0.2409 \\
\hline INV & 0.402916 & 0.231762 & 1.738488 & 0.1002 \\
\hline TER & -0.008539 & 0.003667 & $-2.328562^{\star}$ & 0.0325 \\
\hline R-squared & 0.663422 & \multicolumn{2}{|c|}{ Mean dependent var } & 2.592174 \\
\hline Adjusted R-squared & 0.564429 & \multicolumn{2}{|c|}{ S.D. dependent var } & 2.554639 \\
\hline S.E. of regression & 1.686006 & \multicolumn{2}{|c|}{ Akaike info criterion } & 4.102060 \\
\hline Sum squared resid & 48.32449 & \multicolumn{2}{|c|}{ Schwarz criterion } & 4.398276 \\
\hline Log likelihood & -41.17369 & \multicolumn{2}{|c|}{ F-statistic } & 6.701677 \\
\hline Durbin-Watson stat & 1.719909 & \multicolumn{2}{|c|}{ Prob(F-statistic) } & 0.001278 \\
\hline
\end{tabular}

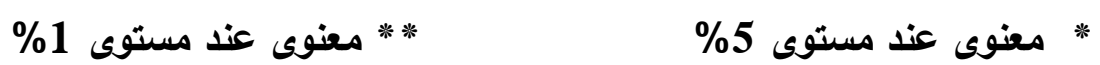
المصدر : من إعداد الباحث اعتماداً على مخرجات البرنامج الاحصائى (E-Views) 3/3/3/4 أثر الإرهاب على الإنفاق الحكومى 
يعرض الجدول (6) نتائج تحليل العلاقة بين الناتج المحلى الاجمالى، المعونة الخارجية،

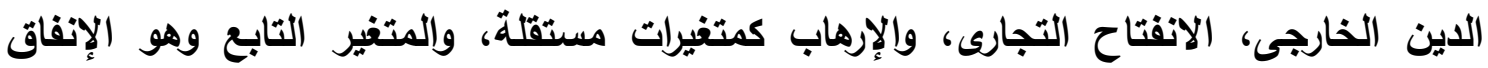
الحكومى، وذلك خلال الفترة (2018-1996) باستخدام أسلوب الانحدار المتعدد في الصورة الخطية. جدول (6) العوامل المؤثرة على الإنفاق الحكومى

\begin{tabular}{|c|c|c|c|c|}
\hline \multicolumn{5}{|c|}{ Dependent Variable: GOV } \\
\hline \multicolumn{5}{|c|}{ Method: Least Squares } \\
\hline \multicolumn{5}{|c|}{ Sample: 19962018} \\
\hline \multicolumn{5}{|c|}{ Included observations: 23} \\
\hline Variable & Coefficient & Std. Error & t-Statistic & Prob. \\
\hline C & 15.94787 & 6.490678 & 2.457042 & 0.0251 \\
\hline GDP & 0.103423 & 0.021519 & $4.806221^{\star \star}$ & 0.0002 \\
\hline FD & -0.299454 & 0.112280 & $-2.667028^{\star}$ & 0.0163 \\
\hline AID & 5.672902 & 1.318706 & $4.301870^{\star \star}$ & 0.0005 \\
\hline TO & 0.039356 & 0.116612 & 0.337495 & 0.7399 \\
\hline TER & -0.033666 & 0.005443 & $-6.185084^{\star \star}$ & 0.0000 \\
\hline R-squared & 0.799096 & \multicolumn{2}{|c|}{ Mean dependent var } & 28.88783 \\
\hline Adjusted R-squared & 0.740007 & \multicolumn{2}{|c|}{ S.D. dependent var } & 6.888278 \\
\hline S.E. of regression & 3.512299 & \multicolumn{2}{|c|}{ Akaike info criterion } & 5.569877 \\
\hline Sum squared resid & 209.7162 & \multicolumn{2}{|c|}{ Schwarz criterion } & 5.866093 \\
\hline Log likelihood & -58.05359 & \multicolumn{2}{|c|}{ F-statistic } & 13.52353 \\
\hline Durbin-Watson stat & 1.279052 & \multicolumn{2}{|c|}{ Prob(F-statistic) } & 0.000020 \\
\hline
\end{tabular}

$$
\text { \%1 }
$$

المصدر : من إعداد الباحث اعتماداً على مخرجات البرنامج الاحصائى (E-Views)

وتثثير النتائج إلى أن المعادلة المقدرة ثبتت معنوية العلاقة عند مستوى 1\% وذلك وفقاً لقيمة ف المحسوية والتى بلغت حوالى 13.5 وهى أكبر من نظيرتها الجدولية عند نفس المستوى

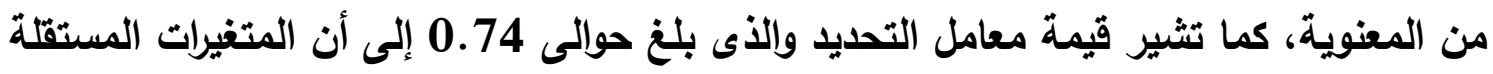
تؤثر فى الاستثمار الأجنبى المباشر بنسبة 74\%، كما أظهرت النتائج وجود علاقة طردية بين 
كل من الناتج المحلى الإجمالى والمعونة الخارجية كمتغيرات مستقلة وإلمتغير التابع وهو الإنفاق

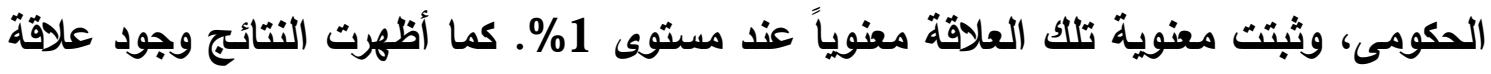
عكسية بين كل من الدين الخارجى وحوادث الارهاب خلال فترة الدراسة (1996 - 1908 - 2108) كمتغيرات

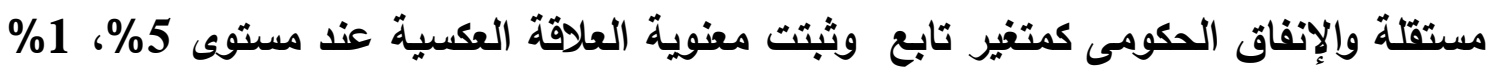

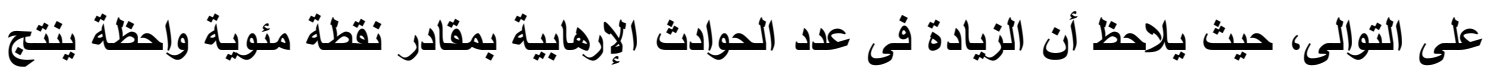
عنها انخفاض فى الإنفاق الحكومى كنسبة من الناتج المحلى الإجمالى بمقار مئوية. 4/3/3/4 أثر الإرهاب على الاخل من السياحة يعرض الجدول (7) نتائج تحليل العلاقة بين متوسط دخل الإدهابه الفرد فى أهم الدول الجالبة

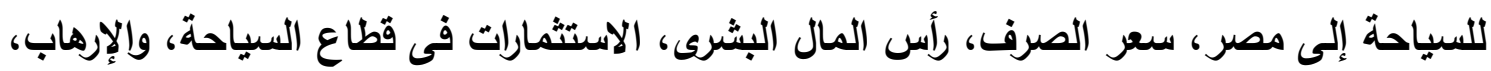
كمتغيرات مستقلة، والمتغير التابع وهو الاخل من قطاع السياحة. وذلك خلال الفترة (19962018) باستخدام أسلوب الانحدار المتعدد فى الصورة الخطية.

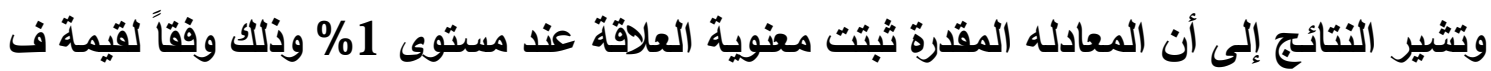
المحسويه والى بلفت حوالى 11.5 وهى أكبر من نظيرتها الجدولية عند نفس المستوى من

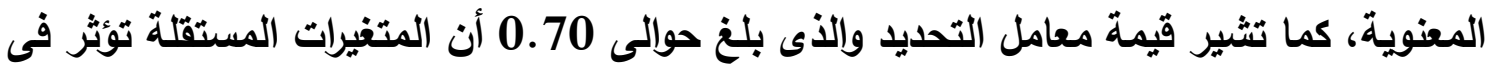
الاستثمار الأجنبى المباشر بنسبة 70\%، كما أظهرت النتائج وجود علاقة طردية بين متوسط دخل

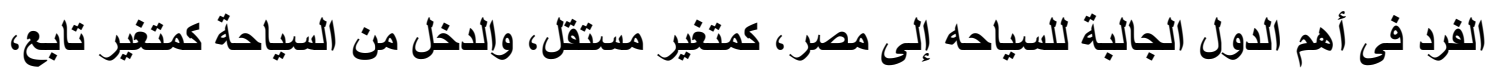

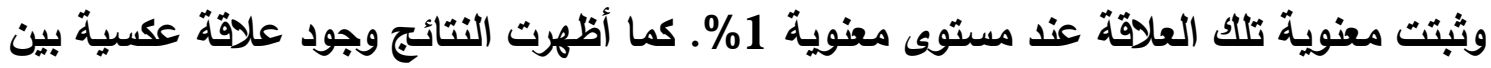
كل من سعر الصرف الأجنبى وحوادث الارهاب كمتغيرات مستقلة وبين الاخل من السياحة كمتغير

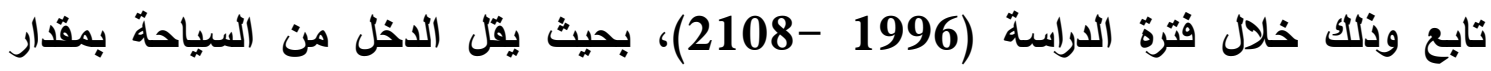
0.002069 نقطة مئوية مع كل زيادة فى حوادث الإرهاب قدرها نقطة مئوية واحدة، وثبته

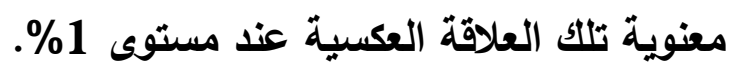


جدول (7) أثر الإرهاب على الاخل من السياحة

\begin{tabular}{|c|c|c|c|c|}
\hline \multicolumn{5}{|c|}{ Dependent Variable: TOR } \\
\hline \multicolumn{5}{|c|}{ Method: Least Squares } \\
\hline \multicolumn{5}{|c|}{ Sample: 1996 2018 } \\
\hline Included observations: 23 \\
\hline Variable & Coefficient & Std. Error & t-Statistic \\
\hline C & -6.542319 & 2.643599 & -2.474777 & 0.0242 \\
\hline FPER & 0.000932 & 0.000228 & $4.091441^{\star *}$ & 0.0008 \\
\hline ER & -0.132987 & 0.039455 & $-3.370592^{\star *}$ & 0.0036 \\
\hline HC & -15.37193 & 10.01534 & -1.534839 & 0.1432 \\
\hline INVT & 0.141152 & 0.134294 & 1.051069 & 0.3079 \\
\hline TER & -0.002069 & 0.000668 & $-3.095331^{\star *}$ & 0.0066 \\
\hline R-squared & 0.772216 & Mean dependent var & 2.410000 \\
\hline Adjusted R-squared & 0.705221 & S.D. dependent var & 0.817352 \\
\hline S.E. of regression & 0.443769 & Akaike info criterion & 1.432434 \\
\hline Sum squared resid & 3.347828 & Schwarz criterion & 1.728650 \\
\hline Log likelihood & -10.47299 & F-statistic & 11.52644 \\
\hline Durbin-Watson stat & 1.361841 & Prob(F-statistic) & 0.000056 \\
\hline
\end{tabular}

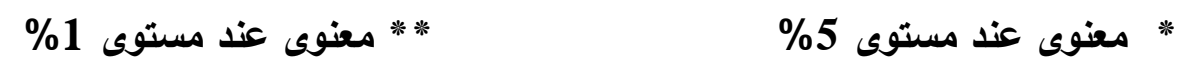

$$
\begin{aligned}
& \text { المصدر : من إعداد الباحث اعتماداً على مخرجات البرنامج الاحصائى (E-Views) }
\end{aligned}
$$

1/5 خلاصة النتائج

إن نتائج التحليل القياسى تتفق إجمالاً مع ما تذهب إليه النظرية الاقتصادية وأيضاً معظم الدراسات التطبيقية، حيث يؤثر الإرهاب سلبياً على النمو بشكل مباشر بحيث إذا زاد الإرهاب بنقطة إنها مئوية واحدة فإن النمو الاقتصادى يقل بمقار 0.002084 نقطة مئوية. كما اتضح أن أهم العوامل المؤثرة على النمو الاقتصادى كانت: الاستثمار المحلى والاستثمار الأجنبى المباشر والاخل مأل من السياحة، وكل منها يرتبط بعلاقة طردية معنوية مع معدل النمو. 
وقد بينت النتائج أن الإرهاب يؤثثر سلبياً ومعنوياً على كل من الاستثمار المحلى والاستثمار الأجنبى المباثر والاخل من السياحة، حيث أن الزيادة فى الإرهاب بنقطة مئوية واحدة تقلئل الاستثمار الأجنبى المباشر بمقار 0.008539 نقطة مئوية، وتقلل الاستثمار المحلى بمقدار

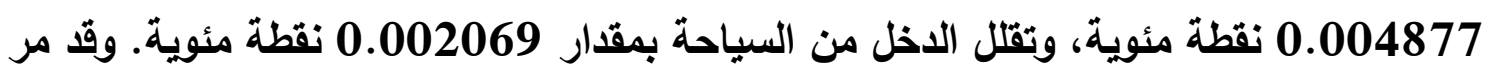
بنا أن تلك المتغيرات الثلاثة هى الأكثر تأثيراً على النمو فى النموذج المقترح، بينما يؤثر الإرهاب

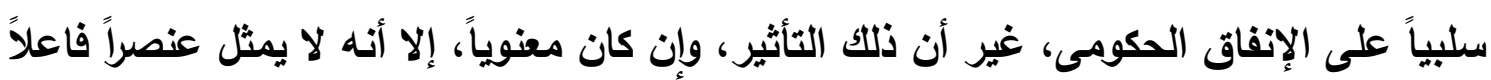

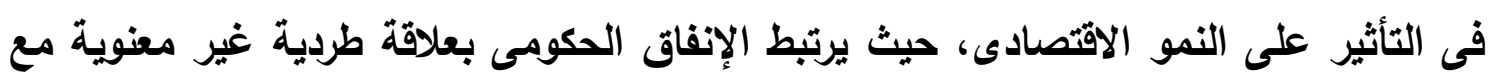
النمو.

\section{2/5 التوصيات والدراسات المستقبلية}

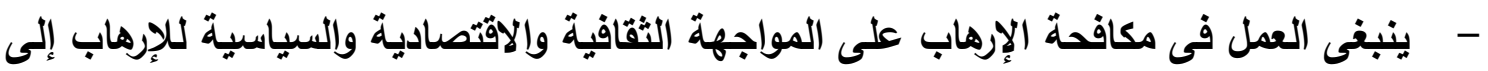

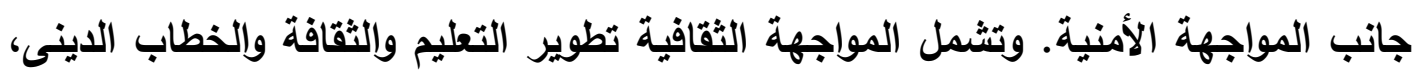

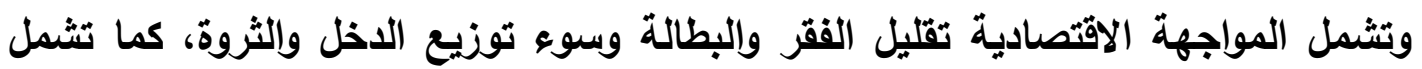
المواجهه السياسية تدعيم الحكم الايمقراطى والمشاركة السياسية وحقوق الإنسان.

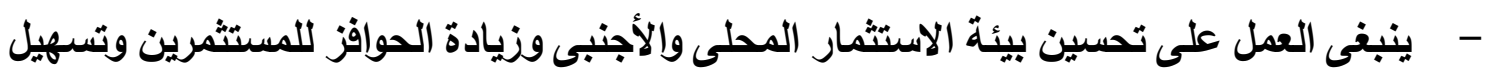

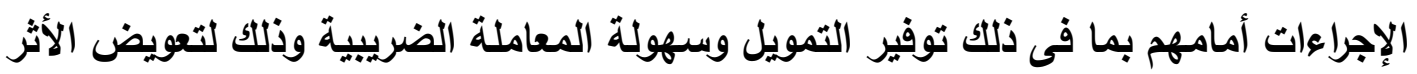

$$
\text { السلبى المحتمل للإرهاب على الاستثمار. }
$$

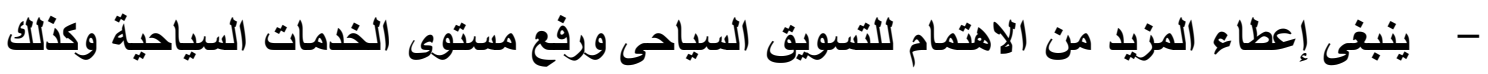

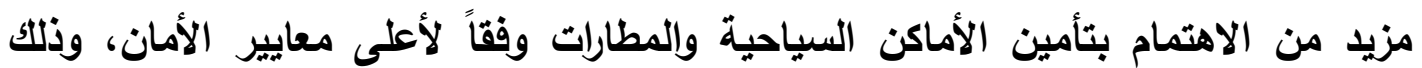

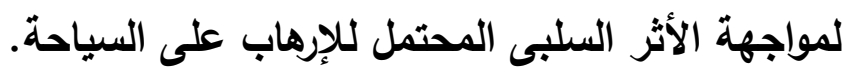
3/5 الدراسات المستقبلية

يوصى الباحث بإعطاء مزيد من الاهتمام لبحث جذور الإرهاب وأسبابه والوزن النسبى للعوامل

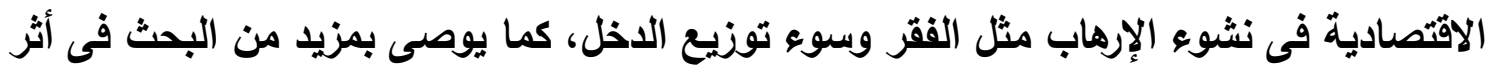

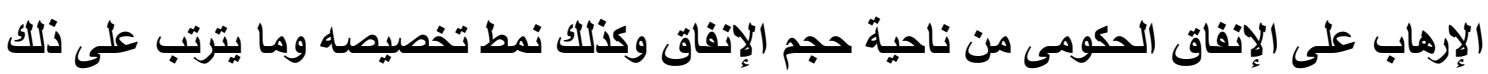
من آثار اجتماعية وإقتصادية. 


\section{قائمة المراجيع}

أولاً: المراجع العربية:

بسيونى، محمد (2019)، "حصاد الإرهاب في مصر خلال ثمانى سنوات: من الوادي والدلتا

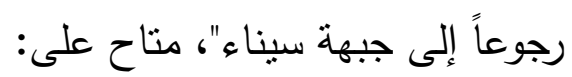

https://www.independentarabia.com/node/8666/

البنك المركزى المصرى، التقرير السنوى، أعوام مختلفة.

جلولى، نسيمة، عبدلى، لطيفة (2018)، "محددات النمو الاقتصادى بدول الثرق الأوسط وشمال

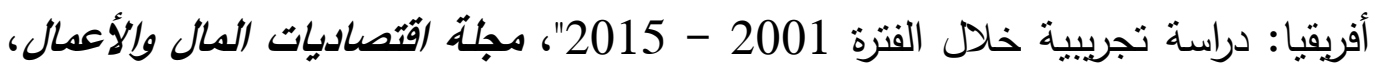

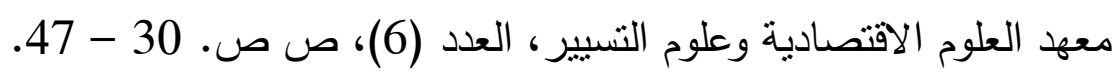
حسن، على عبد الزهرة ، شومان، عبد اللطيف حسن (2013)، "تحليل العلاقات التوازنية طويلة

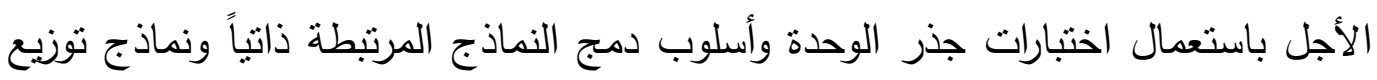
الإبطاء (ARDL)، المجلة العراقية للعطوم الاقتصادية ، المجلد التاسع، العدد الرابع والثثلاثون.

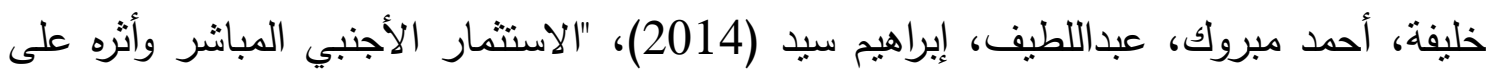

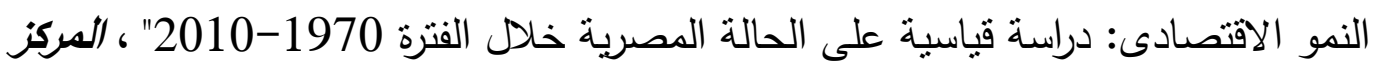

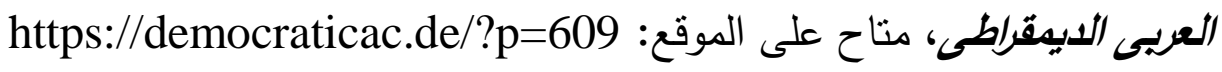

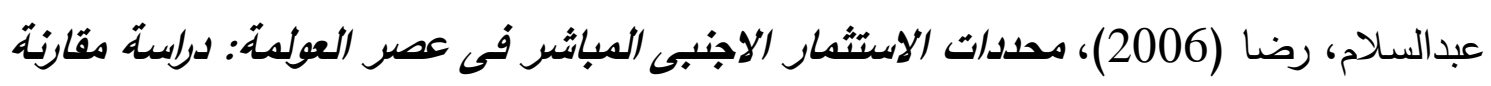

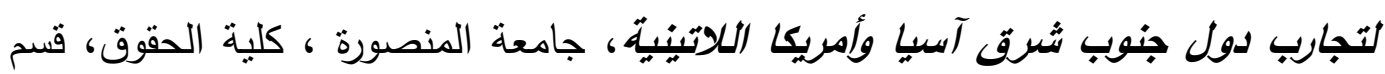
الاقتصاد والمالية العامة. عطية، جمال محمود (2002)، تأثير الاستثمار الاجنبى المباشر على النمو الاقتصادى: دلرسة تطبيقية على الاقتصاد المصرى، رسالة دكتوراة غير منشورة، كلية التجارة، جامعة حلوان.

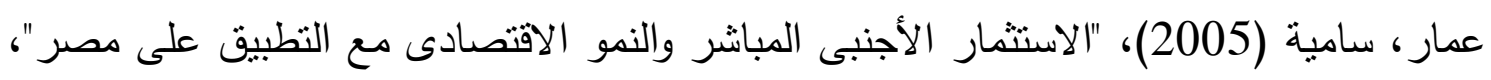

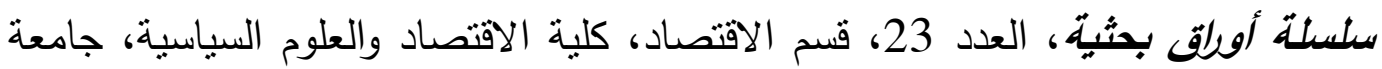

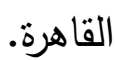

عمارة، أميرة محمد، البحيرى، نجوى محمد (2018)، "محددات النمو الثامل فى مصر"، المجلة

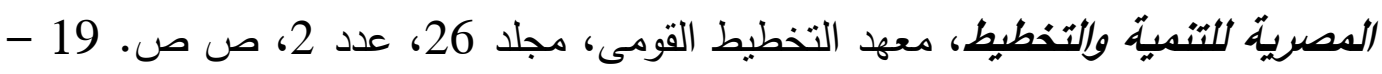


مركز المعلومات ودعم اتخاذ القرار (2008)، "الاستثار الاجنبى المباشر فى العالم كيف نطور فى

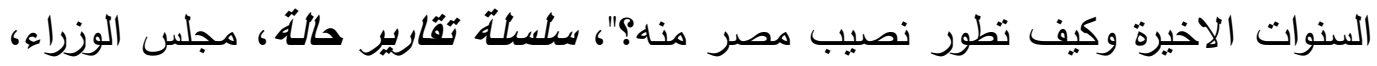

مركز المعلومات و دعم اتخاذ القرار، العدد (2).

مصطفى، محمد جال (2013)، أثر الإهاب على معدل النمو الإقتصادى فى مصر ، رسار، رسالة ماجنتير غير منشورة، كلية التجارة، جامعة المنصورة.

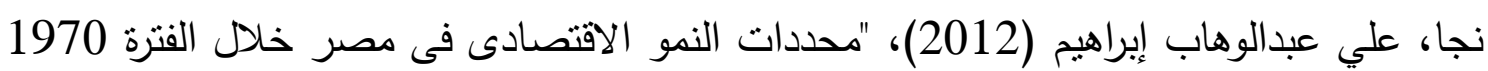
- 2009: دراسة تحليلية قياسية"، مجلة كلية الحقوق للبحوث القانونية والاقتصادية، كلية

$$
\begin{aligned}
& \text { الحقوق، جامعة الإسكندرية، العدد (1)، ص ص. } 632 \text { - } 569 . \\
& \text { وزارة التخطيط والتتمية الاقتصادية، بيانات الحسابات القومية. } \\
& \text { ثانياً: المراجع الأجنية: }
\end{aligned}
$$

Abadie, A. (2006), "Poverty, Political Freedom, and the Roots of Terrorism", The American Economic Review, 96(2), 50-56.

Abadie, A. and Gardeazabal, J. (2008), "Terrorism and the World Economy", European Economic Review, (52) 1-27

Abadie, A., and Gardeazabal, J. (2003), "The Economic Costs of Conflict: A Case Study of the Basque Country", American Economic Review, 93(1), 113-132.

Alesina, A., and Roberto, P. (1996), "Income Distribution, Political Instability, and Investment", European Economic Review, 40(6), 1203-1228.

Alomar, M. and El-Sakka, M. (2011), "The Impact of Terrorism on the FDI Inflows to Less Developed Countries: A Panel Study", European Journal of Economics, 38, 116-125.

Barro, R., and Sala-I-Martin, X. (2004), Economic growth, 2nd Edition, MIT Press, Cambridge.

Barth, J., Li, T., McCarthy, D., Phumiwasana, T., and Yago, G. (2006), Economic Impacts of Global Terrorism: From Munich to Bali, Research Report, Milken Institute.

Basu, K. and Marg, V. S. (2010), "Impact of Political Instability and Terrorism in the Tourism Industry of Three Middle-East Countries:

An Econometric Exploration", Available at:

http://www.ijbtsjournal.com/images/main 1366796758/0002-Kaushik.pdf 
Blomberg, S., Broussard, N., and Hess, G. (2011), "New Wine in Old Wineskins? Growth, Terrorism and the Resource Curse in Sub-Saharan Africa", European Journal of Political Economy, 27(S1), S50-S63.

Blomberg, S., Hess, G., and Orphanides, A. (2004) "The Macroeconomic Consequences of Terrorism", Journal of Monetary Economics, 51(5), 1007-1032.

Blomberg, S., Hess, G., and Weerapana, A. (2004), "Economic Conditions and Terrorism", European Journal of Political Economy, 20(2), 463478.

Cinar, M. (2017), "The Effects of Terrorism on Economic Growth: Panel Data Approach", Proceedings of Rijeka School of Economics, 35(1), 97-121.

Crain, N. and Crain, W. (2006), "Terrorized Economies", Public Choice, 128(1-2), 317-349.

Dobronogov, A. and Iqbal, F. (2005), Economic Growth in Egypt: Constraints and Determinants, World Bank, Working Paper Series No. 42, October 2005.

Eckstein, Z. and Tsiddon, D. (2004), "Macroeconomic Consequences of Terror: Theory and the Case of Israel", Journal of Monetary Economics, 51(5), 971-1002.

Enders, W. and Sandler T. (2006), The Political Economy of Terrorism, Cambridge, Cambridge University Press, New York.

Enders, W. and Sandler, T. (2008), "Economic Consequences of Terrorism in Developed and Developing Countries: An Overview", in: Keefer, P., and Loayza, N. (2008), Terrorism, Economic Development, and Political Openness, Cambridge University Press, New York.

Faragalla, W. (2017), "Econometric Analysis for Tourism Demand Function in Egypt: a Dynamic Panel Data Approach", Facta Universitatis, Series: Economics and Organization, 14(4), $321-332$.

Frey, B., Luechinger, S., and Stutzer, A. (2007), "Calculating Tragedy: Assessing the Costs of Terrorism", Journal of Economic Survey, 21(1), 1-24.

Gaibulloev, K., Sandler, T. (2008), "Growth Consequences of Terrorism in Western Europe", Kyklos, 61(3), 411-424.

Gaibulloev, K., Sandler, T. (2009), "The Impact of Terrorism and Conflicts on Growth in Asia", Economics and Politics, 21(3), 359-383. 
Ganor, B. (2002), "Defining Terrorism: Is One Man's Terrorist Another Man' Freedom Fighter?", Police Practice and Research: An International Journal, 3(4), 287-304.

Gries, T., Kriegery, T. and Meierrieks, D. (2009), "Causal Linkages between Domestic Terrorism and Economic Growth", Defence and Peace Economics, 22(5), 493-508.

Gupta, S. et al. (2004), "Fiscal Consequences of Armed Conflict and Terrorism in Low- and Middle-Income Countries", European Journal of Political Economy, 20(2), 403-421.

Gylfason, T. (1999), Principles of Economic Growth, Oxford University Press, UK.

Hammam, R. (2010), Determinants of Egypt's economic growth for the period 1985-2007, American University in Cairo, Available at: http://dar.aucegypt.edu/handle/10526/671

Herrera, S., Selim, H., Youssef, H., and Zaki, C. (2010), Egypt beyond the Crisis Medium-Term Challenges for Sustained Growth, The World Bank, Policy Research Working Paper 5451.

Krueger, A. and Maleckova, J. (2003), "Education, Poverty and Terrorism: Is There a Causal Connection?", Journal of Economic Perspectives, 17(4), 119-144.

Meierrieks, D. and Gries, T. (2012a), "Causality between Terrorism and Economic Growth", Journal of Peace Research, 50(1) 91-104.

Meierrieks, D. and Gries, T. (2012b), "Economic Performance and Terrorist Activity in Latin America, Defence and Peace Economics, 23(5), 447470.

Mirza, D., and Verdier, T. (2008), "International Trade, Security, and Transnational Terrorism: Theory and a Survey of Empirics", Journal of Comparative Economics, 36(2), 179-194.

Mohamed, T. and Elseyoufi, T. (2018), "Terrorism in the Middle East: Implications on Egyptian Travel and Tourism", International Journal of Religious Tourism and Pilgrimage, 6(3), Article 7.

Ocal, N. \& Yildirim, J. (2013), "Analysing the Determinants of Terrorism in Turkey Using Geographically Weighted Regression, Defence and Peace Economics, 24(3), 195-209.

Ocal, N. and Yildirim, J. (2010), "Regional Effects of Terrorism on Economic Growth in Turkey: A Geographically Weighted Regression Approach", Journal of Peace Research, 47(4), 477-489. 
Tavares, J. (2004), "The Open Society Assesses its Enemies: Shocks,

Disasters and Terrorist Attacks", Journal of Monetary Economics, 51(5), 1039-1070.

Todaro, M. and Smith, S. (2012), Economic Development, 11th ed., Pearson Education, Inc., Boston, USA.

Venieris, Y. and Gupta, D. (1986), "Income Distribution and Sociopolitical

Instability as Determinants of Savings: A Cross-sectional Model", Journal of Political Economy, 94(4), 873-883.

Virgo, J. (2001), "Economic Impact of the Terrorist Attacks of September 11, 2001", Atlantic Economic Journal, 29(4), 353-357.

Zakaria, M., Jun, W., and Ahmed, H. (2019), "Effect of Terrorism on Economic Growth in Pakistan: An Empirical Analysis", Economic Research-Ekonomiseka Istrazivanja, 32(1), 1794-1812. 


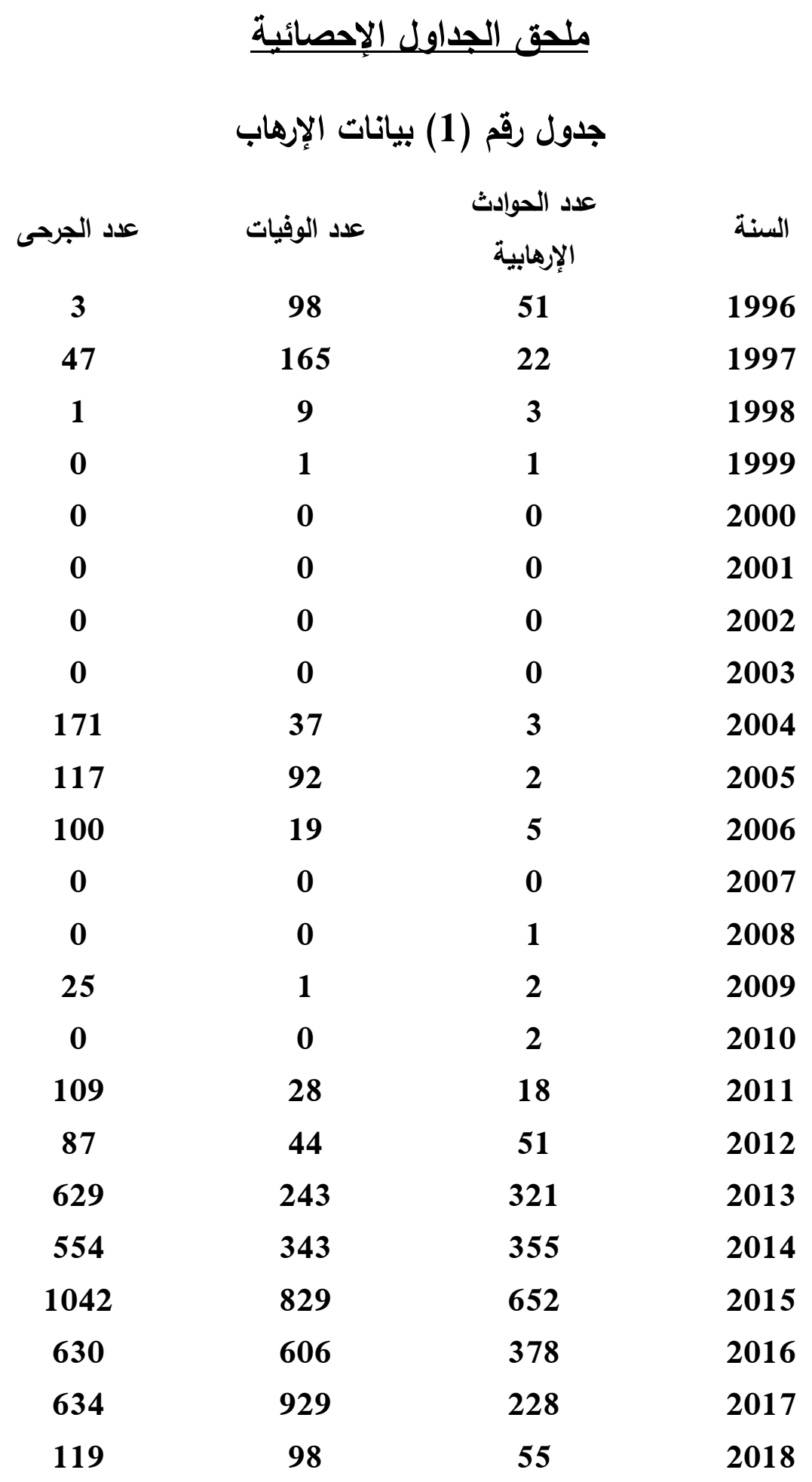

المصدر: قاعدة البيانات الدولية للإرهاب (GTD) المتاحة على الموقع الإكترونى:

https://www.start.umd.edu/research-projects/global-terrorism-database-gtd 
الجدول رقم (2) بيانات النمو الاقتصادى ويعض محدداته فى مصر

\begin{tabular}{|c|c|c|c|c|c|}
\hline رأس المال & ناتج قطاع & الإنفاق & الاستثمار & الاستثمار & معدل نمو \\
\hline البشرى & السياحة & الحكومى & الآجنبى & المحلى & الناتج \\
\hline$(\mathrm{HC})$ & (TOR) & (GOV) & & (INV) & (GRW) \\
\hline
\end{tabular}

$\begin{array}{lllllll}0.548 & 1.51 & 29.82 & 0.94 & 18.13 & 4.99 & 1996\end{array}$

$\begin{array}{lllllll}0.591 & 1.55 & 27.05 & 1.14 & 17.56 & 5.49 & 1997\end{array}$

$\begin{array}{lllllll}0.592 & 1.24 & 26.53 & 1.27 & 21.50 & 5.58 & 1998\end{array}$

$\begin{array}{lllllll}0.605 & 1.30 & 28.30 & 1.17 & 21.62 & 6.05 & 1999\end{array}$

$\begin{array}{lllllll}0.611 & 1.56 & 28.06 & 1.24 & 19.55 & 6.37 & 2000\end{array}$

$\begin{array}{lllllll}0.616 & 1.61 & 28.90 & 0.52 & 18.26 & 3.54 & 2001\end{array}$

$\begin{array}{lllllll}0.621 & 1.82 & 28.41 & 0.74 & 18.00 & 2.39 & 2002\end{array}$

$\begin{array}{lllllll}0.623 & 1.97 & 28.62 & 0.29 & 16.89 & 3.19 & 2003\end{array}$

$\begin{array}{lllllll}0.629 & 2.77 & 31.11 & 1.59 & 16.94 & 4.09 & 2004\end{array}$

$\begin{array}{lllllll}0.635 & 3.29 & 31.91 & 5.99 & 17.98 & 4.47 & 2005\end{array}$

$\begin{array}{lllllll}0.643 & 3.23 & 35.75 & 9.34 & 18.73 & 6.84 & 2006\end{array}$

$\begin{array}{lllllll}0.651 & 3.64 & 31.25 & 8.87 & 20.85 & 7.09 & 2007\end{array}$

$\begin{array}{lllllll}0.659 & 3.74 & 33.00 & 5.38 & 22.39 & 7.16 & 2008\end{array}$

$\begin{array}{lllllll}0.660 & 3.46 & 35.36 & 3.55 & 19.19 & 4.67 & 2009\end{array}$

$\begin{array}{lllllll}0.666 & 3.48 & 31.81 & 2.92 & 19.50 & 5.15 & 2010\end{array}$

$\begin{array}{lllllll}0.669 & 3.19 & 33.62 & 0.20- & 17.10 & 1.76 & 2011\end{array}$

$\begin{array}{lllllll}0.676 & 2.66 & 30.15 & 1.00 & 16.03 & 2.23 & 2012\end{array}$

$\begin{array}{lllllll}0.681 & 2.79 & 30.55 & 1.45 & 14.21 & 2.19 & 2013\end{array}$

$\begin{array}{lllllll}0.683 & 2.11 & 31.81 & 1.51 & 13.64 & 2.92 & 2014\end{array}$

$\begin{array}{lllllll}0.690 & 2.38 & 29.65 & 2.08 & 14.29 & 4.37 & 2015\end{array}$

$\begin{array}{lllllll}0.695 & 1.81 & 30.58 & 2.44 & 15.04 & 4.35 & 2016\end{array}$

$\begin{array}{lllllll}0.696 & 1.89 & 32.76 & 3.15 & 15.27 & 4.18 & 2017\end{array}$

$\begin{array}{lllllll}0.700 & 2.43 & 30.83 & 3.24 & 16.66 & 5.31 & 2018\end{array}$

- وزارة التخطيط والتنمية الاقتصادية، بيانات الحسابات القومية.

UNDP, Human Development Report, different years. -

World Bank Database - 
جدول رقم (3) محدات المتغيرات الوسيطة

\begin{tabular}{|c|c|c|c|c|c|c|c|c|}
\hline الاستثمار & 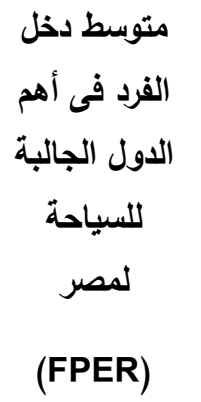 & الخارجية & $\begin{array}{c}\text { الخارجى } \\
\text { (FD) }\end{array}$ & 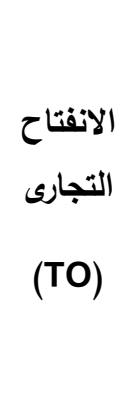 & سعرف & اللقطاع الائتمان & $\begin{array}{l}\text { الإجمالى } \\
\text { الناتى } \\
\text { (GDP) }\end{array}$ & السنة \\
\hline 2.70 & 17521 & 3.22 & 46.30 & 24.48 & 3.39 & 36.53 & 108.53 & 1996 \\
\hline 4.82 & 17935 & 2.55 & 37.94 & 21.84 & 3.39 & 39.69 & 114.49 & 1997 \\
\hline 1.43 & 18326 & 2.30 & 37.75 & 22.75 & 3.39 & 46.56 & 120.87 & 1998 \\
\hline 3.75 & 18684 & 1.78 & 34.12 & 21.59 & 3.40 & 52.00 & 128.19 & 1999 \\
\hline 2.79 & 19342 & 1.37 & 29.14 & 19.89 & 3.47 & 51.95 & 136.35 & 2000 \\
\hline 3.73 & 19582 & 1.32 & 28.85 & 18.64 & 3.97 & 54.93 & 141.17 & 2001 \\
\hline 4.03 & 19651 & 1.48 & 33.52 & 20.85 & 4.50 & 54.66 & 144.55 & 2002 \\
\hline 3.16 & 20057 & 1.22 & 36.54 & 24.55 & 5.85 & 53.90 & 149.16 & 003 \\
\hline 3.14 & 20575 & 1.89 & 39.58 & 32.48 & 6.20 & 54.04 & 155.27 & 2004 \\
\hline 2.84 & 21025 & 1.17 & 34.19 & 39.43 & 5.78 & 51.17 & 162.21 & 2005 \\
\hline 2.80 & 21581 & 0.84 & 28.72 & 40.96 & 5.73 & 49.29 & 173.31 & 2006 \\
\hline 2.46 & 22038 & 0.86 & 26.28 & 43.17 & 5.64 & 45.52 & 185.60 & 2007 \\
\hline 2.65 & 22110 & 1.03 & 20.66 & 45.82 & 5.43 & 42.80 & 198.88 & 2008 \\
\hline 2.65 & 21108 & 0.5 & 18 & 9 & 5.54 & 36.09 & 20 & 2009 \\
\hline 1.89 & 21583 & 0.28 & 17.14 & 36.26 & 5.62 & 33.07 & 218.89 & 2010 \\
\hline 2.50 & 22178 & 0.18 & 15.30 & 37.89 & 5.93 & 31.15 & 222.75 & 2011 \\
\hline 2.26 & 22285 & 0.66 & 14.67 & 35.30 & 6.06 & 27.39 & 227.71 & 2012 \\
\hline 2.74 & 22279 & 1.96 & 16.54 & 32.99 & 6.87 & 26.22 & 232.69 & 2013 \\
\hline 1.08 & 22579 & 1.19 & 14.00 & 30.65 & 7.08 & 25.61 & 239.47 & 2014 \\
\hline 2.23 & 22818 & 0.77 & 15.24 & 25.53 & 7.69 & 26.32 & 249.94 & 2015 \\
\hline 0.79 & 23091 & 0.74 & 21.06 & 24.41 & 10.03 & 34.13 & 260.81 & 2016 \\
\hline 0.64 & 23435 & 0.01 & 36.58 & 37.06 & 17.78 & 28.52 & 271.71 & 2017 \\
\hline 0.63 & 23833 & 0.84 & 40.35 & 39.71 & 17.77 & 25.53 & 286.15 & 2018 \\
\hline
\end{tabular}

- مزارة التخطيط والتتمية الاقتصادية، بيانات الحسابات القومية.

World Bank Database 